\title{
Title: Brain Circuitry of Compulsivity
}

Authors: Odile A. van den Heuvel ${ }^{1,2,3}$, Guido van Wingen ${ }^{4}$, Carles Soriano-Mas ${ }^{5,6}$, Pino Alonso ${ }^{5,7}$, Samuel R. Chamberlain ${ }^{8,9}$, Takashi Nakamae ${ }^{10}$, Damiaan Denys ${ }^{4}$, Anna E. Goudriaan ${ }^{11,12}$, Dick J. Veltman ${ }^{1}$

Affiliations:

${ }^{1}$ Department of Psychiatry, VU University medical center (VUmc), Amsterdam, The Netherlands

${ }^{2}$ Department of Anatomy \& Neurosciences, VUmc, Amsterdam, The Netherlands

${ }^{3}$ Department of Psychology, The Obsessive-Compulsive Disorder Team, Haukeland University Hospital, Bergen, Norway.

${ }^{4}$ Department of Psychiatry, Academic Medical Center, University of Amsterdam, Amsterdam, The Netherlands

${ }^{5}$ OCD Clinical and Research Unit, Department of Psychiatry, Bellvitge University Hospital; Bellvitge Biomedical Research Institute (IDIBELL), and CIBERSAM (Centro de Investigación en Red de Salud Mental), Carlos III Health Institute, Barcelona, Spain

${ }^{6}$ Department of Psychobiology and Methodology in Health Sciences, Universitat Autònoma de Barcelona, Spain

${ }^{7}$ Department of Clinical Sciences, Bellvitge Campus, University of Barcelona, Spain ${ }^{8}$ Department of Psychiatry, University of Cambridge, Cambridge, United Kingdom

${ }^{9}$ Cambridge and Peterborough NHS Foundation Trust (CPFT), Cambridge, United Kingdom

${ }^{10}$ Department of Psychiatry, Graduate School of Medical Science, Kyoto Prefectural University of Medicine, Kyoto, Japan

${ }^{11}$ Academic Medical Center, Department of Psychiatry, Amsterdam Institute for Addiction Research, University of Amsterdam, Amsterdam, The Netherlands

${ }^{12}$ Arkin Mental Health and Jellinek Addiction Treatment, Amsterdam, The Netherlands

Corresponding author:

Dr. O.A. van den Heuvel, MD PhD.

Department of Psychiatry, VU university medical center, Amsterdam, the Netherlands 
Tel +31-20-4440196, Fax +31-20-4440197

Email: oa.vandenheuvel@vumc.nl

\begin{abstract}
:
Compulsivity is associated with alterations in the structure and the function of parallel and interacting brain circuits involved in emotional processing (involving both the reward and the fear circuits), cognitive control, and motor functioning. These brain circuits develop during the pre-natal period and early childhood under strong genetic and environmental influences. In this review we bring together literature on cognitive, emotional, and behavioral processes in compulsivity, based mainly on studies in patients with obsessive-compulsive disorder and addiction. Disease symptoms normally change over time. Goal-directed behaviours, in response to reward or anxiety, often become more habitual over time. During the course of compulsive disorders the mental processes and repetitive behaviours themselves contribute to the neuroplastic changes in the involved circuits, mainly in case of chronicity. On the other hand, successful treatment is able to normalize altered circuit functioning or to induce compensatory mechanisms. We conclude that insight in the neurobiological characteristics of the individual symptom profile and disease course, including the potential targets for neuroplasticity is an unmet need to advance the field.
\end{abstract}

Key words: cortico-striato-thalamico-cortical circuits, limbic, compulsivity, anxiety, neuroimaging

Word count abstract: 172

Word count text (excluding references): 8664

Number of references: 180

Number of figures: 1

Number of tables: 2

Acknowledgements:

Dr. Soriano-Mas is funded by a 'Miguel Servet' contract from the Carlos III Health Institute (CP10/00604). Dr. Goudriaan is supported by a VIDI innovative research grant (grant no. 91713354) funded by the Dutch Scientific Research Association (NWO-ZonMW). Dr. Alonso was founded by the Instituto de Salut Carlos III-FIS 
PI14/00413. Dr. Nakamae received grant support from MEXT KAKENHI (No. 24791223 and No. 26461753.

Disclosures:

Dr. Chamberlain consults for Cambridge Cognition. Dr. van den Heuvel received grant support from PhotoPharmics and speaker's honorarium from Lundbeck. 
'Compulsivity' may be defined as the performance of repetitive, unwanted and functionally impairing overt or covert behaviors without adaptive function, performed in a habitual or stereotyped fashion, either according to rigid rules or as a means of avoiding perceived negative consequences (Fineberg et al. 2014). Probably the most known mental disorder characterized by compulsivity is the obsessive-compulsive disorder (OCD). But compulsivity is also a key feature in addictive disorders, Tourette's syndrome, impulse control disorders in Parkinson's disease, and the socalled obsessive-compulsive and related disorders (OCRDs), such as trichotillomania and body dysmorphic disorder. Most brain imaging literature on compulsivity comes from studies in OCD. These studies mainly focused on alterations in the structure and the function of parallel and interacting brain circuits involved in emotional processing (involving both the reward and the fear circuits), cognitive control, and motor functioning. These brain circuits develop during the pre-natal period and early childhood and mature until adulthood. Alterations in neurodevelopment seem to underlie vulnerability to disease, but at the same time chronic symptomatology results in neuroplastic changes. Brain structure and function alter during the course of disease, with behaviours typically changing from mainly goal-directed to more habitual. This review aims to give a broad perspective on brain network hypotheses in OCD and other disorders characterized by compulsivity, based on brain imaging studies probing different aspects of compulsivity. After a 'historical' description of the brain circuits studied in compulsivity, we describe the complex influence of impulsivity, anxiety and cognitive control on these circuits. Subsequently, we summarize the literature on how brain function and structure change during development, disease course, and in response to treatment. The overall goal of this paper is not to give a complete overview of the literature but to generate new perspectives on potential targets for intervention, ideally taking into account the symptom profile and disease stage of the individual patient, irrespective of his/her diagnosis.

\section{The frontal-striatal circuits}

A convergence of neuroimaging research points to the involvement of parallel, partly segregated, cortico-striato-thalamo-cortical (CSTC) circuits in behavioral control functions involving motor, cognitive, affective and motivational processes (Alexander 
et al. 1986; Cummings et al. 1993; Groenewegen \& Uylings 2000). These CSTC circuits involve direct and indirect pathways projecting from the specific cortical areas to the specific sub-regions of the striatum and thalamus with recurrent projections to the cortex. In the direct pathways an excitatory glutamatergic signal projects to the striatum, sending an inhibitory GABA-ergic signal to the internal part of the globus pallidus. This results in disinhibition of the thalamus and an increased excitatory effect on the cortex. In the indirect pathways, the striatum projects an inhibitory signal to the external part of the globus pallidus and the subthalamic nucleus, sending an excitatory signal to the internal part of the globus pallidus. The net effect is an increased inhibition of the thalamus and decreased excitation on the cortex. In this way the direct pathway functions as a self-reinforcing positive feedback loop and contributes to the initiation and continuation of behaviors, whereas the indirect pathway provides a mechanism of negative feedback which is important for the inhibition of behaviors and switching between behaviors. Normal human behavior relies on a flexible balance between initiation and inhibition of behavior and abnormalities within these pathways contribute to various maladaptive behaviours seen in mental disorders, such as OCD (Graybiel \& Rauch 2000; Mataix-Cols \& van den Heuvel 2006; Menzies et al. 2008; Milad \& Rauch 2012), Tourette's syndrome (Groenewegen et al. 2003), trichotillomania (Chamberlain et al. 2009), impulse control disorders in Parkinson's disease (van den Heuvel et al. 2010; Vriend et al. 2014), and addictive disorders (Everitt \& Robbins 2005).

The OCRDs share behavioral characteristics such as compulsivity. Brain imaging studies have been focused historically most extensively on OCD, but overlapping findings have been reported in OCRDs as well. Also considerable overlap exists with the studies in addictive disorders. Generally speaking, brain imaging studies in OCD show that an imbalance exists both between the direct and indirect pathways within specific CSTC circuits and between the parallel CSTC circuits involved in the various domains of behavior (see for some reviews Graybiel \& Rauch 2000; Mataix-Cols \& van den Heuvel 2006; Menzies et al. 2008; Milad \& Rauch 2012; van den Heuvel et al. 2010). The interpretation of the brain imaging findings developed over time, and so also the 'disease models'. For long, the OCD model proposed a disbalance between a hyper-activated ventral 'emotional', or motivational, circuit (due to dominance of direct pathway) and a hypo-activated dorsal 'cognitive' circuit (due to dominance of the indirect pathway) (Mataix-Cols \& 
van den Heuvel 2006). The ventral circuit, connected with the limbic brain regions, is important for the appraisal of emotional significance of situations and the generation of emotional responses and reward-based behaviours. The dorsal circuit, with strong involvement of the associative cortices, is crucial for the subsequent modulation of the initial response, by top-down control over the ventral circuit. In this simplified working model of OCD the hyper-activated ventral 'emotional' circuit explains the increased anxiety and repetitive behaviours, and the hypo-activated dorsal 'cognitive control' circuit explains the cognitive control deficits and inability to modulate emotional and behavioural responses (Phillips et al. 2003a, 2003b).

More recently, based on the insight that within the ventral prefrontal cortex important differentiation exists between affective and cognitive processes, and that some control processes are more ventral than the classical executive functions such as working memory and planning, Milad \& Rauch (2012) proposed three instead of two important CSTC circuits for OCD: the 'affective circuit', the 'ventral cognitive circuit' and the 'dorsal cognitive circuit' (Milad \& Rauch, 2012). The affective circuit, connecting the ventromedial prefrontal cortex and anterior cingulate cortex with the nucleus accumbens and the thalamus, is relevant for affective and reward processing. The dorsal cognitive circuit, connecting dorsolateral prefrontal cortex, the caudate nucleus and the thalamus, is crucial for executive functions such as working memory and planning. The ventral cognitive circuit, connecting anterolateral orbitofrontal cortex, anterior part of the putamen and thalamus, is involved in motor preparation and response inhibition (Milad \& Rauch, 2012).

After the initial focus of brain imaging studies on the orbitofrontal cortex and the ventral striatum, whole brain imaging studies (both structural and functional) increasingly reported the involvement of brain regions outside the frontal-striatal brain areas (Menzies et al. 2008). Optimal higher-order cognitive processing, for instance, also relies on strong fronto-parietal connections, mainly between the lateral prefrontal cortices and the inferior parietal lobe / sulcus. During development these fronto-parietal connections develop and increasingly contribute to the integration of multiple first-order (e.g., visuospatial, semantic, temporal) associations to reach higher-order associations (Wendelken et al. 2015). This so-called 'relational thinking' is necessary to learn associations among stimuli in our environment higher-order relational comparisons (Vendetti \& Bunge 2014). 
Since the discussion on the key feature of OCD, being anxiety or compulsivity, and the decision to shift OCD from the anxiety disorders category to the obsessive-compulsive and related disorders category in the DSM-5 (APA, 2013), brain imaging studies in OCD increasingly focused on the compulsive aspects, using paradigms focusing on reward learning, response inhibition, and habit learning. Also trans-diagnostic comparatives studies have been initiated, although still scarce relative to the mono-diagnostic studies being published predominantly. This development in thinking about the disorders introduced the sensorimotor circuit as $4^{\text {th }}$ relevant CSTC circuit in the disease model. The associative striatum (involving mainly the caudate nucleus) is especially active during early stages of goal-directed behavior, but with extended training, it's contribution gradually reduces (Thorn et al. 2010). The sensorimotor CSTC circuit, connecting the (pre)motor cortex, putamen and thalamus, then increasingly mediates automatic responding and the transition from goal-directed to habitual behaviors. This leads to an increase in stimulus-response-like habitual behaviors involving the sensorimotor part of the striatum (mainly the posterior part of the putamen) and, at a certain stage, decreased dependence on striatal dopaminergic projections (Ashby et al. 2010).

- insert figure here -

Although the parallel CTSC circuits largely are segregated, it is evident that complex behaviors depend on between-circuit communication since the involved sub-processes subserved by different CSTC circuits cannot be executed independently.

The communication between the 'affective' (or motivational) circuit and the sensorimotor circuit is especially important for habit learning and compulsivity. Several ways of communication and integration between the circuits have been described. One mechanism of integration might be via the dopaminergic projections at the striatal level (Groenewegen et al. 2003). The balance between goal-directed and habitual behavior also depends on the top-down control processes involving the ventral and dorsal 'cognitive' circuits. In the context of human behaviors and the development of mental disorders, it is important to realize that adaptive and maladaptive behaviors 'evolve' during neurodevelopment across the life span and during the course of the disease, associated with shifts within and between the 
involved circuits. Below we discuss these transitions during the various stages of development and disorder and the between-circuit interactions involved.

Most brain imaging studies cited in this review concern structural and functional MRI studies. Conventional task-related fMRI experiments primarily focus on task-related activation of individual brain areas. However, fMRI also allows studying activity within networks of brain areas and the interactions between brain areas. In this way, fMRI can investigate not only which specific brain areas are involved in a task, but also how functionally connected brain regions communicate (Stephan, 2004) and how this varies under different conditions. This development converted our 'brain region'thinking into a more 'brain network'-thinking. Psycho-physiological interaction (PPI) analyses, for example, can be used to examine how functional connectivity between seed regions and the rest of the brain is altered by psychological variables (i.e. task conditions) (Friston et al. 1997). In order to study the direction of the altered connectivity dynamic causal modeling (DCM) can be used (Friston et al. 2003). The combined analysis of fMRI (or electrophysiology) data and measures of structural connectivity (e.g., using diffusion tensor imaging) increases our insight in the relation between functional networks and the structural wiring. Recent developments in the quantitative analysis of complex networks, based largely on graph theory, have been rapidly translated to studies of brain network organization. Both anatomical connections in the brain and the communication between neurons exhibit 'small-world topology' (Bullmore \& Sporns 2009; 2012), as most other networks that require for instance efficient communication (e.g. social media) or transport (e.g. underground). The Human Connectome Project is building a "network map" of the anatomical and functional connectivity within the healthy human brain (see the open-access database at http://www.humanconnectomeproject.org), and also produces a body of data that will facilitate future research into brain disorders. It will also contribute to our understanding of how brain networks evolve during normal development, how disease influences network functioning, and how interventions interact with it.

\section{Cognitive control, the role of the ventral and dorsal cognitive control circuits}

Neural correlates of compulsivity have been primarily assessed in cognitive flexibility tasks (e.g., probabilistic reversal learning task (O’Doherty et al. 2001)). Also, 
response inhibition paradigms (e.g., Stop Signal task (Logan 1994), Go-NoGo task (Donders 1969) and more general higher-order executive functions, including planning (e.g. Tower of London task, (Shallice 1983)) and working memory (e.g. Nback task, (Gevins \& Cutillo 1993)) seem to be relevant to explain cognitive control impairments in compulsive disorders. Moreover, to probe the interaction between the ventral and dorsal cognitive control circuits with the limbic areas, emotion regulation (or reappraisal) paradigms, which by definition involve executive control over emotions, have been developed (Ochsner et al. 2014).

Impaired probabilistic reversal learning in OCD is associated with hypofunction of bilateral orbitofrontal and parietal cortices, both in patients with OCD and unaffected relatives (Chamberlain et al. 2008). Similarly, Remijnse et al. (2013) showed decreased lateral orbitofrontal activation in OCD during probabilistic reversal learning, accompanied by increased putamen and anterior cingulate activation. Other authors have shown that perceptual shifting is more associated with engagement of the parietal cortex (Ravizza and Carter 2008). Remijnse et al. (2006) also showed decreased activation in the more dorsal parts of the prefrontal cortex during probabilistic reversal learning in OCD patients. A human lesion study, however, showed that the dorsolateral prefrontal cortex plays a more general role in executive functioning (including attention) and not reward-related reversal learning per se, while lesions of the orbitofrontal cortex (only in case of bilateral lesions) result in clear impairments in probabilistic reversal learning (Hornak et al. 2004). Task switching, conversely, is associated with engagement of the dorsal parts of the prefrontal cortex (Ravizza and Carter 2008). This is consistent with the proposition of Milad et al. (2012) to differentiate between the ventral and dorsal 'cognitive control' circuits. Also here there is no strict segregation between these dorsal and ventral circuits and many cognitive paradigms used in fMRI studies involve a combination of multiple cognitive processes related to partly segregated and partly overlapping neural circuits.

Response inhibition can be considered an operationalization of certain aspects of both impulsivity and compulsivity (Bari \& Robbins 2013). Response inhibition largely depends on a proper function of the inhibition network, which is mainly right lateralized, with the inferior frontal cortex and pre-supplementary motor area (preSMA) as key components of the network. From here the stop signal goes to the motor cortex through CSTC projections, also involving parietal regions, anterior insula, 
cingulate cortex and the dorsolateral prefrontal cortex (Chambers et al. 2009; Sebastian et al. 2013a). For an extended review on the neural correlates of motor response inhibition and interference in obsessive-compulsive spectrum disorders, see van Velzen (2014), summarizing the results of fMRI studies on interference control (Flancker task, Simon task, Stroop task), action restraint (Go-NoGo task) and action cancellation (Stop Signal task) in OCD, ADHD, Tourette's syndrome, and trichotillomania. Based on this overview, it can be concluded that patients within the impulsive-compulsive spectrum, both the hyperdopaminergic disorders (e.g. OCD, Tourette, trichotillomania) and the hypodopaminergic disorders (e.g., ADHD, Parkinson's disease), exhibit the same deficits in response inhibition due to altered recruitment of the inhibition network. The behavioral and neural deficits are also present in unaffected siblings of the patients (Chamberlain et al. 2007, Menzies et al. 2007; de Wit et al. 2012). Whether these inhibition-related brain areas are hypo- or hyperactivated depends on the complexity of the paradigm and the ability to compensate. As an example, the Stop Signal task exerts higher demands on subjects, and thus puts higher strain on the compensational resources of the inhibition network, compared to the Go-NoGo task (Sebastian et al. 2013b), and is thus more sensitive to detect inhibition impairments in patients. The altered recruitment of the dorsal cognitive control system in OCD and related disorders, related to impaired response inhibition, and other relevant executive functions such as cognitive flexibility, planning and working memory, seems to be at least partly related to altered connectivity with the limbic regions (van den Heuvel et al. 2011; de Vries et al. 2014; van Velzen et al. 2014, van Velzen et al. 2015).

The interaction between cognitive control circuits and the limbic areas is specifically relevant for emotion regulation. The ability to manage emotional information is central to our daily functioning (Ochsner et al. 2002; Ochsner \& Gross 2005). When emotion regulation, i.e., the process of moderating the emotional impact of a certain thought or stimulus through cognitive reinterpretation (Gross 2013), is impaired the individual is at risk to develop mental diseases, including mood (Erk et al. 2010), anxiety (Ball et al. 2012), addictive (Fox et al. 2007), and obsessivecompulsive disorders (Jacobs et al. 2012). A recent fMRI study in cocaine-dependent individuals revealed that impaired emotion regulation was related to decreased activation in brain areas related to emotion regulation and decreased functional connectivity between prefrontal cortex and the amygdala during reappraisal of 
negative emotions (Albein-Urios et al. 2014). Impaired recruitment of the dorsal prefrontal areas and altered limbic responding during effortful emotion regulation is also found in OCD (de Wit et al. 2015) and unipolar and bipolar depression (Rive et al. 2015), suggesting that it is a more general feature in most mental disorders. However, although not specifically related to compulsivity, impaired emotion regulation, accompanied by increased limbic activation and decreased dorsal cognitive control activation, contributes to maladaptive behaviors, including habits. As an example of this, Goodwin et al. (2014) recently showed in a longitudinal follow-up study in 572 adolescents that compulsive exercise was predicted by dysfunctional emotion regulation strategies.

From impulsivity to compulsivity, shift from ventral to dorsal CSTC

The CSTC loops are less segregated than initially thought. Anatomical evidence suggests a more integrated system, with information cascading from one loop to the next (Haber \& Knutson 2010). In literature, there is a common belief, particularly based on animal research, that gradually over time a specific functional shift occurs from impulsivity to compulsivity, and from goal-directed to habitual behavior, associated with a specific anatomical shift.

Impulsivity is a risk factor for the development of addictive disorders (Slutske et al. 2012) and relapse after remission (Stevens et al. 2014; Verdejo-García et al. 2008). In a rat model of cocaine addiction, high impulsivity predicts the development of addiction-like behaviors in rats, including persistent or compulsive drug taking in the face of aversive outcomes (Belin et al. 2008).

As described above, the striatum is a key structure in modulating behavioral responses that are under the control of both action-outcome and stimulus-response mechanisms, by incentive motivational processes and Pavlovian associations, respectively. Most evidence for this impulsive to compulsive shift comes from classic animal studies on addiction, suggesting a shift from ventral to more dorsal domains of the striatum in animals with compulsive drug use, i.e. continuing use despite adverse consequences (Everitt \& Robbins, 2005). During the development of addictive behaviours the initial dopamine-dependent, striato-nigro-striatal ascending routes from the nucleus accumbens, underlying action-outcome mechanisms under the influence of protracted exposure to addictive drugs, shift to recruitment of more 
dorsal and posterior regions of the striatum, mainly the putamen, underlying stimulusresponse mechanisms in the control over drug seeking behaviors (Belin et al. 2009). However, based on recent findings by Murray et al. (2014), impulsivity per se does not seem to be the facilitating factor in this ventral-to-dorsal intra-striatal shift. Studying the effects of dopamine blockage in the dorsolateral striatum of rats (using bilateral infusions of the dopamine receptor antagonist $\alpha$-flupenthixol) on cocaine seeking behavior at different stages of training, they found a delayed shift from ventral to dorsal striatal dopaminergic control over cocaine use in high-impulsive rats compared to low-impulsive rats (Murray et al., 2014). This suggests that although impulsivity has been identified as a key marker of the individual propensity to swift from controlled to compulsive drug use (Belin et al. 2008) and is characterized by low ventral striatal dopamine receptor availability (Dalley et al. 2007), it does not simply facilitate the ventral-to-dorsal shift at the neuronal level. One might explain these findings by the interacting cortico-striatal processes related to impaired response inhibition and cognitive flexibility, contributing to decreased cognitive control over maladaptive inflexible behaviors.

Computational models supported this idea (Piray et al. 2010; Egbert \& Barandiaran 2014). Egbert and Barandiaran (2014), for example, recently developed an elegant dynamic computational sensorimotor model for the study of habits that, unlike the traditional stimulus-response-probabilities based models, assumes a more dynamic transition and interaction between stimulus-response and action-outcome forms of behaviours, involving simultaneous activation in multiple CSTC circuits. The model is based on the assumption that habits are self-maintaining patterns of behaviour in a complex ecological context, where trajectories taken through the sensorimotor space increase the likelihood that in the future similar trajectories will be taken, under influence of reinforcing and inhibiting parallel processes.

Unlike the large body of literature on compulsivity in animals, human studies supporting the ventral-to-dorsal shift are rare. A functional MRI (fMRI) study in heavy drinkers versus social drinkers showed decreased cue reactivity in the ventral striatum in heavy drinkers compared to social drinkers, suggesting that the shift from ventral to dorsal striatal reactivity takes place relatively early (Vollstadt-Klein et al., 2010). Another fMRI study, with a more severe group of alcohol-dependent patients 
(mean duration 15 years alcohol dependence) showed over-reliance on habit learning in alcohol-dependent patients accompanied by an increased recruitment of posterior putamen and a decreased recruitment of the anterior putamen and ventromedial prefrontal cortex (Sjoerds et al. 2013). This fits with the finding that longer duration of alcohol dependence is associated with lower activity of the ventromedial prefrontal cortex, suggestive of increasingly diminished ventral route involvement with development of chronicity. Alcohol-dependent patients, compared with healthy controls, are more prone to develop habitual response patterns in context of possible wins, reflected in stronger posterior caudate and putamen activity during a gambling task (van Holst et al. 2014). In a recent fMRI study on habit formation in OCD patients, Gillan et al. (2015) tested, using a shock avoidance paradigm, whether habits in OCD primarily arise from dysfunction in the goal-directed (ventral) or the habit (dorsal) system. Excessive habit formation in OCD patients was associated with hyperactivation of the caudate nucleus, not the putamen. Although the authors interpret the findings as supportive for a failure in the goal-directed system, one might also explain the hyperactivation of the caudate nucleus during habit formation as a compensatory mechanism in the dorsal cognitive control system. This fits with the findings of other fMRI studies on cognitive control in OCD, showing compensatory hyperactivation of the executive network during response inhibition (de Wit et al. 2012) as well as working memory (de Vries et al. 2014) in both OCD patients and their unaffected siblings.

In short, although there is some evidence for a ventral-to-dorsal shift underlying the development of compulsive behaviours, the findings are not yet conclusive and more complex interactions between related circuits seem to be involved as well, such as a failure of the dorsal executive control system as well as the interference from the limbic system. Functional connectivity studies can contribute to a better insight on these complex within and between-network interactions.

From anxiety to compulsivity, the role of the limbic circuit

The majority of studies that investigated the neural basis of compulsivity have focused on the cortico-striatal network. Although repetitive behavior is at the core of compulsive disorders, anxiety and distress are important symptoms in many OCRDs 
as well. OCD was classified as anxiety disorder in the previous versions of the DSM and shares many behavioral and neural characteristics with other anxiety disorders, such as harm avoidance, feelings of uncertainty, hyper-responsiveness of the limbic system, and impaired cognitive control on emotion. Also trichotillomania and skinpicking disorder often cause significant distress, and a negative emotional state (including anxiety) is part of the withdrawal symptoms in drug addiction. Whereas repetitive actions are particularly associated with the cortico-striatal network, negative affect is typically associated with increased activity in the limbic circuit. Although the limbic circuit is ill defined, it is considered to consist of subcortical structures such as the amygdala, hippocampus, anterior thalamus, fornix, mammillary bodies, as well as the cingulate gyrus (MacLean 1949). All these brain structures potentially have a role in compulsivity, but the amygdala may be of particular interest because of its wellestablished role in anxiety and its strong integration within the cortico-striatal system (Cho et al. 2013). It is crucial for the detection of salient events, and can initiate a cascade of psychological and physiological processes that lead to an anxious state (Davis \& Whalen 2001; Ulrich-Lai \& Herman 2009). As such, it may be optimally situated to guide behavior when faced with aversive as well as appetitive stimuli (Cardinal et a. 2002; Balleine 2005).

Due to its clear relatedness to other anxiety disorders, the involvement of the limbic system in compulsivity is most often investigated in OCD. Initial studies that have investigated limbic functioning in this disorder have used techniques to measure blood flow or glucose metabolism at rest. A meta-analysis reported consistent differences in neural activity in the orbitofrontal cortex and caudate nucleus, but found no consistent evidence for differences in other brain regions (Whiteside et al. 2004). Later studies noted that the limbic regions come into play when obsessivecompulsive symptoms are induced by confronting patients with their feared stimuli (Breiter et al. 1996). A meta-analysis of these so-called symptom provocation studies showed consistent activation in multiple regions in the prefrontal cortex including the anterior cingulate cortex, precuneus, superior temporal gyrus, insula, caudate nucleus, posterior cingulate cortex, and superior parietal lobule. No consistent amygdala activation was reported, even though increased activation in close proximity of the amygdala in the hippocampus and uncus was demonstrated (Rotge et al. 2008). However, several studies that were not included in the meta-analysis have reported amygdala activation, suggesting that the experience of obsessive-compulsive 
symptoms is also associated with amygdala activation (Adler et al. 2000; van den Heuvel et al. 2004; van den Heuvel et al. 2005; Simon et al. 2010; Simon et al. 2014; de Wit et al. under review). Yet other studies have investigated whether the amygdala is also more responsive to more general emotional stimuli, not directly related to OCD symptoms, which is often the case in other anxiety disorders (Etkin et al. 2007). Initial studies suggested that amygdala reactivity to emotional faces was actually reduced (Britton et al. 2010; Cannistraro et al. 2004), which suggested that OCD may be different from other anxiety disorders by lacking generalized amygdala hypervigilance. However, more recent studies do suggest increased amygdala reactivity to emotional face stimuli as well (Cardoner et al. 2011; Via et al. 2014). These apparent opposite results could in part be explained by methodological differences, such as implicit versus explicit emotion perception and active versus passive task performance. The later studies also showed increased activity in a widespread network of brain regions outside the amygdala, including the frontoparietal network, orbitofrontal cortex, thalamus, and insula (Cardoner et al. 2011; Via et al. 2014). Together, these studies suggest that activity in the limbic system is not particularly altered during rest, but that it is more responsive to emotional stimuli and recruited during the experience of OCD symptoms.

To investigate the integration of the limbic system with the cortico-striatal network, more recent studies have used functional connectivity analyses by analyzing the correlation between time-courses in these brain regions, which is thought to reflect the level of functional interaction. Such studies reported increased amygdala connectivity with the fronto-parietal network during emotional face processing, (Cardoner et al. 2011), working memory performance (de Vries et al. 2014), and response inhibition (van Velzen et al., 2015). Conversely, reduced amygdala connectivity with the anterior cingulate and orbitofrontal cortices during a risky choice game or with the nucleus accumbens during the anticipation of gains and losses has been reported (Admon et al. 2012; Jung et al. 2013). Recent studies have also investigated connectivity of the cortico-striatal network with the limbic network during rest, and have predominantly found reduced functional connectivity between these networks, which may in part be related to aggressive symptoms (Jung et al. 2013; Harrison et al. 2013; Gottlich et al. 2014). These studies suggest that the interaction between the limbic and cortico-striatal networks is altered in OCD. 
Connectivity can be enhanced as well as reduced, which may be dependent on the state of the patient.

Limbic network activity and its integration with the cortico-striatal network has mainly been investigated in OCD, but similar differences in limbic-cortico-striatal network connectivity have been reported in addiction (Ma et al. 2010) as well as trichotillomania (White et al. 2013). These mechanisms may therefore also be involved in other disorders characterized by compulsivity, but needs to be investigated in future studies.

\section{Neurodevelopment and neuroplasticity}

The brain is in continuous development and adaptation, under influence of genetic, behavioral and environmental factors. Neuroplastic changes occur due to normal agerelated changes during life span (involving both neurodevelopmental and neurodegenerative processes), due to presence of chronic and often recurrent symptoms of compulsivity, and under influence of therapeutic interventions. Nevertheless, since most imaging results in psychiatry (including OCD, addiction and related disorders) are based on cross-sectional studies in mostly adult patients, strong conclusions on the neuroplastic changes during the various stages of development and disease are difficult to make.

During normal development, processes relevant for cognitive control are assumed to shift from initial ventral areas during early childhood to more dorsal regions during adolescence and adulthood, by gradual maturation of the dorsal circuit (Perlman \& Pelphrey 2010, 2011; Gogtay et al. 2004). One might hypothesize that a 'dorsal-ventral imbalance' due to altered brain development (early in life), may hamper cognitive control and increase the vulnerability to neuropsychiatric disorders such as compulsive disorders. CSTC circuits develop from infancy to adolescence (Colibazzi et al. 2008). Since the dorsal cognitive CSTC circuit matures only relatively late during adolescence, which continues into early adulthood (Arnsten \& Rubia 2012), individuals seem to be more vulnerable to the development of compulsive behaviors during this developmental stage. Children with compulsive disorders show alterations in, at least partly, similar brain circuits as adults. There are, however, also differences, related to the onset of disease and the development of specific CSTC circuits. Children with OCD, for instance, display more neurological 
signs than adults with OCD, such as tics or choreiform movements, which suggests a greater involvement of the sensorimotor CSTC circuit (Geller et al. 1996). Montigny et al. (2013) observed that in a very large sample of 1938 adolescents, compulsive behavior was associated with increased right striatum volume (similar to what is observed in adults), but also with increased gray matter volume in right dorsolateral and bilateral orbitofrontal cortices (contrary to what is normally observed in adults).

Later in life, some compulsive disorders, such as OCD, are associated with age-related increases in ventral striatal volumes (Pujol et al. 2004; de Wit et al. 2014), and altered age-related neurodegeneration of the limbic brain areas (de Wit et al. 2014), probably related to chronic compulsivity, anxiety and compensatory processes. Finally, with advancing age, specific alterations in the CSTC circuits seem to underlie compulsive behaviors in for instance frontotemporal dementia (Perry et al. 2012) and Parkinson's disease (Vriend et al. 2014).

During the whole lifespan the brain circuits remain plastic. The neuroplasticity of the brain is an entrance to therapeutic interventions. Since most literature on the relationship between treatment effects and changes in brain structure and function is based on studies in OCD, we here present a short summary of the findings so far in this disorder.

\section{a. Neuroplastic effects of cognitive behavioral therapy}

Cognitive-behavioral therapy (CBT), based mainly on exposure and response prevention, is the psychological treatment of choice for OCD and has demonstrated to be highly effective in reducing obsessive-compulsive and related symptoms. The analysis of CBT-related changes at the level of brain areas and circuits may contribute to the elucidation of neural mechanisms involved in the pathophysiology of the disorder as well as in its response to different therapeutic approaches.

Although some studies failed to detect any significant structural change in response to CBT in pediatric and adult OCD patients (Rosenberg et al. 2000; Hoexter et al. 2012), others reported a volume increase of OFC gray matter (GM) and capsula externa white matter (WM) in children and adolescents with OCD after CBT (Huyser et al. 2013), maintained at two years follow-up (Huyser et al. 2014). A normalization of reduced GM and WM parietal volumes following combined pharmacological and CBT treatment has been also reported in pediatric OCD patients (Lázaro et al. 2009), 
suggesting some kind of structural plasticity in response to the modulatory effects of CBT.

Initial positron emission tomography and single photon emission computed tomography studies in OCD reported a decrease in right caudate activity in CBT treatment responders, associated with the reduction of obsessive-compulsive symptom severity (Baxter et al. 1992; Schwartz et al. 1996; Nakatani et al. 2003), although conflicting findings have been also reported (Apostolova et al. 2010). Significant decreases in regional brain activity have also been described in prefrontal (both ventral and dorsal) cortices and thalamus (Nakatani et al. 2003; Saxena et al. 2009; Yamanishi et al. 2009), as well as increases in dorsal anterior cingulate cortex (Saxena et al. 2009) and posterior (occipital and parietal) regions (Yamanishi et al. 2009).

CBT-induced changes in task-related brain activation patterns have been analyzed for various dorsal and ventral cognitive control processes. For the Stroop task, results have been inconsistent as both increased (Nakao et al. 2005) and decreased (Nabeyama et al. 2008) prefrontal and temporal activation has been observed. Using a reversal learning task, Freyer et al. (2011) found, in OCD patients versus controls, decreased OFC and right putamen activation before treatment, and increased caudate nucleus activity in response to CBT. Since these findings were obtained at a lenient threshold only, these should be regarded as preliminary. In adolescent OCD patients, Huyser et al. (2010) demonstrated a significant decrease in reversal learning-related prefrontal activity in response to CBT. Changes in symptom severity correlated with changes in prefrontal and parietal activation patterns. The same authors (Huyser et al. 2011) reported increased anterior cingulate activation during error detection and increased bilateral insular activation during high-conflict trials, which was age-dependent and only partially affected by successful CBT. Overall, results of task-related changes in response to CBT suggest at least a partial normalization of pre-treatment differences between OCD patients and controls in response to CBT, but findings have been inconsistent and are in need of replication in larger samples.

Studies in OCD investigating neural responses during symptom provocation before and after CBT are scarce. Using a pre-post design, Nakao et al. (2005) reported decreased activation in the putamen, cerebellum and orbitofrontal, anterior cingulate, insular, and temporal cortices during a symptom provocation task in a small sample of 
10 OCD patients, six of whom received CBT. Morigiève et al. (2014) recently corroborated these findings in a large-scale fMRI study, showing decreased responses to obsession-inducing images in the anterior cingulate and the orbitofrontal cortex in OCD patients treated with CBT.

Studies using proton magnetic resonance spectroscopy to analyze changes on different brain biochemical compounds in response to CBT have likewise been scarce, and their results inconsistent. Both Benazon et al. (2003) and Zurowski et al. (2012) failed to detect any significant change on glutamatergic compounds and myoinositol concentration in response to CBT in OCD patients, although in the last study myo-inositol concentration in the OFC predicted the outcome to CBT. In contrast, O'Neill et al. (2012) reported a decrease of N-acetyl-aspartate (NAA) and creatinine concentrations in left pre-genual ACC and an increase of choline compounds in right thalamus in response to $\mathrm{CBT}$ in pediatric OCD patients that correlated with clinical improvement.

Information on brain structure and function might be useful in the future to predict treatment response to CBT. Recent morphological studies have indicated that larger medial prefrontal volume (Hoexter et al., 2013) and thinner rostral cingulate cortex (Fullana et al., 2014) were associated with greater CBT-induced symptom reduction in OCD. In contrast, in fluoxetine-treated patients smaller pre-treatment dorsolateral prefrontal volume was associated with greater treatment response, suggesting that brain volume markers might be associated with specific interventions rather than with a non-specific general treatment response. Confirming Hoexter et al.'s results, Hashimoto et al. (2014) have recently reported smaller volumes of ventral prefrontal and anterior cingulate cortices in OCD non-responders to CBT. From a functional perspective, higher pre-treatment resting-state orbitofrontal activity was associated with a better response to CBT (Brody et al. 1998; Yamanishi et al. 2009). In accordance with structural data, the opposite pattern was detected in a small group of patients treated with fluoxetine in whom lower orbitofrontal activity was associated with better response. Using a symptom provocation design, limbic activity was found to be correlated with OCD symptom reduction following CBT, whereas dorsal prefrontal activity prior to therapy was negatively associated with treatment response (Olatunji et al. 2013). Presumably, higher pre-treatment orbitofrontal metabolism may reflect a greater ability to change the assignment of affective value to 
stimuli and to be better able to extinguish habitual, compulsive responses, resulting in a better response to CBT.

It has been proposed that the behavioral component of CBT, i.e., exposure-in vivo and response prevention, may reinstate goal-directed control on the maladaptive habitual behaviors stored in the basal ganglia (Gillan et al. 2011) and the extinction of the pathologically increased limbic response (Delgado et al. 2006). According to this hypothesis, reduction in caudate activity after CBT may reflect procedural learning to acquire new skills. On the other hand, the cognitive part of CBT, mainly involving reappraisal strategies to correct the erroneous cognitive patterns, is associated with increased activation of higher-order frontal regions involved in cognitive control of negative emotion (Clark \& Beck 2010; Ochsner \& Gross 2005). Hyperactivity of these areas during symptom exposure may underlie unsuccessful attempts to implement goal-directed action plans over compulsive habit-like rituals (Gillan et al., 2011). Thus, successful CBT seems to rely on a combination of multiple changes within the various interacting CSTC and limbic circuits, involving enhanced effectiveness of the dorsal cognitive control circuit, increased recruitment of the ventromedial prefrontal cortex (as a key structure involved in extinction of conditioned responses), and reduction in the pathologically increased activation of both the sensorimotor CSTC circuit (associated with a reduction in habitual behavior) and the limbic areas (associated with a reduction in anxiety or distress).

\section{b. Neuroplastic effects of pharmacological interventions}

In addition to investigating the effects of CBT on regional brain morphology and function, a number of studies have investigated the effects of both acute pharmacological challenge and (sub)chronic treatment on brain circuitry function in healthy controls and patients with OCD (see Table 1). In healthy volunteers, serotonin manipulation studies have focused on the limbic system and emotional processing (Harmer \& Cowen 2013) in view of the clinical use of selective serotonin re-uptake inhibitors (SSRIs) for their antidepressant and anxiolytic effects. Generally, SSRIs have been found to shift attention away from more negative or threatening aspects of the environment towards the more positive, and to dampen amygdala responses to emotional stimuli. In a meta-analysis of available single-dose studies, pooling results from different fMRI paradigms, SSRIs modulated activity in the amgydalohippocampal formation, and mediofrontal cortices, during presentation of faces and 
pictures (Outhred et al. 2013). These findings were distinct from those reported with selective noradrenaline reuptake inhibitors, which tended to affect cortical regions alone. Subchronic and chronic (7-28 days) trials in healthy volunteers have also been undertaken. Escitalopram treatment versus placebo was associated with significant reductions in amygdala activation during an emotional face paradigm (Arce et al. 2008) and low dose clomipramine or duloxetine treatments were associated with dampened neural responses to negatively valenced stimuli in the amygdala, anterior cingulate, and insula (de Almeida et al. 2010; van Marle et al. 2011). Duloxetine also affects the encoding and retrieval of such stimuli (Tendolkar et al. 2011). In restingstate fMRI studies, citalopram versus placebo reduced the functional connectivity between the amygdala and the medial prefrontal cortex (McCabe et al. 2011a), and duloxetine reduced the functional connectivity of the default mode network and taskpositive network (van Wingen et al. 2014). Subchronic SSRI treatment seems to reduce reward processing in bilateral nucleus accumbens (erotic videos; Abler et al. 2012) and ventral striatum/medial OFC (chocolate stimuli; McCabe et al. 2010), though subchronic duloxetine treatment increased ventral striatal responses during the anticipation of monetary rewards (Ossewaarde et al. 2011). Citalopram, and to a lesser degree the mixed reuptake inhibitor reboxetine, decreased activation in response to aversive stimuli (mouldly strawberries; MacCabe et al. 2010).

In patients, predominantly in OCD, studies exploring the effects of SSRI intervention on brain function have employed both resting-state and activation designs. Using SPECT, fluvoxamine treatment (without a placebo arm) was found to be associated with reduced cerebral blood flow in the caudate nucleus and putamen, irrespective of treatment response. In contrast, treatment responders, but not nonresponders, exhibited treatment-associated reduced metabolism in the thalamus (Ho Pian et al. 2005). In a recent resting-state fMRI study in OCD, decreased pretreatment small-world neural efficiency tended to normalize following SSRI treatment, with symptom improvement correlating with changes in connectivity in the ventral frontal cortex (Shin et al. 2014). In pediatric OCD, brain activation during a serial reaction time task was measured before and after 6-month open-label naturalistic treatment with behavioural counseling and fluoxetine (Lazaro et al. 2008). OCD patients had higher activation in the middle frontal cortex compared to controls at baseline, whereas activation in the left insula and left putamen decreased over the course of treatment. Due to lack of a control arm and the dual nature of the 
intervention, it is difficult to infer which of these changes (if any) were due to SSRI. In an open-label non-controlled trial, using a spatial N-back task, working memory was found to improve in treatment responders, who showed a more linear relationship between brain activation and task difficulty, contrary to what was found in nonresponders (van der Wee et al. 2007).

In summary, SSRIs in healthy volunteers, given acutely or in sub-chronic dosing regimens, dampen neural responses in the amygdala and related limbic circuitry to anxiety-provoking and negative stimuli, and reduce functional coupling between relevant neural nodes. On the other hand, there is some evidence across studies that SSRI treatment in OCD led to reduced dorsal striatum (putamen/caudate) activity in the resting state. Findings from the few cognitive challenge studies were unclear, with methodological limitations (e.g. inclusion of multiple types of treatment, lack of an appropriate control condition).

Antipsychotic medication increasingly used as an augmentation strategy for treatment resistant $\mathrm{OCD}$, seem to modulate reward circuitry in healthy volunteers. A single dose of sulpiride versus placebo reduced activation in response to rewarding chocolate stimuli in the ventral striatum and anterior cingulate cortex, and also reduced orbitofrontal and insular activation in response to aversive stimuli (McCabe et al. 2011b). Using a monetary reward paradigm (Abler et al. 2007), a single dose olanzapine versus placebo dampened activation in the ventral striatum, anterior cingulate, and inferior frontal cortex. Risperidone treatment in OCD patients nonresponsive to ongoing SSRI treatment was associated with increased metabolism in the striatum, cingulate, prefrontal (especially orbital) cortex, and thalamus (Buchsbaum et al. 2006). Thus, dopamine antagonism dampens reward-related activation in the nucleus accumbens, and reduces activation in response to aversive stimuli in the insula/lateral OFC in healthy controls, while studies in OCD have generally not clearly addressed effects of this medication on emotional and reward processing.

Regarding to brain structure, there is some mixed evidence that SSRI treatment is linked with increases in putamen volumes, and reductions of thalamic and amygdala volumes, and findings for white matter were also mostly inconsistent (see Table 2).

To summarize, initial studies have indicated both similar and distinct brain changes in response to CBT and pharmacotherapy, suggesting both common and 
specific processes related to neuroplastic changes in response to treatment. Overall, caution is warranted with respect to interpreting the majority of OCD SSRI studies considered above, in view of frequent lack of placebo control or randomization, and the high possibility of practice effects and non-specific effects of time, and of indirect effects of reducing non-OCD symptoms such as depression. To help address such limitations, future research should include a variety of complementary measures within the same study (structural MRI, cortical morphology, DTI, resting state fMRI, fMRI disease-relevant cognitive challenge, and fMRI symptom provocation). Such work is likely to require large-scale international collaborations and input from traditionally disparate research fields.

\section{c. Neuroplastic effects of invasive and non-invasive neuromodulation}

In contrast to the more widespread effects of pharmacological treatments, neuromodulatory techniques may enable a more precise targeting of distinct neural circuits. Based on strong hypotheses on the underlying alterations in neural circuitries, OCRDs are particularly suitable for therapeutic modulation of these circuits.

Traditionally, neurosurgery was the only alternative option for severe OCD cases that were non-responding to CBT or pharmacological treatments. Based on a recent consensus guideline on neurosurgery in psychiatry (Nuttin et al. 2014), ablative procedures such as cingulotomy (Banks et al. 2014) and capsulotomy (Rück et al. 2008) as well as the appealing (since less invasive) alternative methods, such as gamma-knife radiosurgery (Lopes et al. 2014) and deep brain stimulation (DBS) (Kisely et al. 2014) should be reserved for the small proportion of severely disabled treatment-resistant cases. Due to the still large proportion of treatment-resistant patients, in combination with the drawbacks of permanent lesioning the brain in case of ablative surgery, there is a strong need to invest in less permanent surgical procedures, such as DBS, and non-invasive alternatives, such as repetitive transcranial magnetic stimulation (rTMS) and transcranial direct current stimulation (tDCS). For a comprehensive overview of the effects of the various neuromodulatory approaches in OCD, see recent review papers (Jaafari et al. 2012; Kisely et al. 2014; Bais et al. 2014; Lefaucheur et al. 2014).

DBS consists of the implantation of two electrodes in specific brain areas of which stimulation parameters (e.g., frequency, pulse width, and intensity) are adjusted manually by a trained clinician. DBS is a unique tool to unravel the anatomical 
circuitry associated with the core symptoms of OCD such as compulsivity, because DBS may be switched on and off instantly in a double-blind fashion, and may be used to record local field potentials from brain regions directly associated with symptom changes. In the past decade, DBS has been applied in over 200 patients worldwide using two different targets, the ventral striatal area and the nucleus subthalamicus. Some will remark that more targets have been explored, but often just the names differ and not the target itself. The ventral capsule, the (ventral part) of the anterior limb of the capsula interna, and the nucleus accumbens, all share a similar positioning on the $\mathrm{x}$ and $\mathrm{z}$-plane but slightly differ in anterior-posterior positioning on the $\mathrm{y}$ plane. What have we learned from DBS enabling us to understand better the circuitry of compulsivity? First, even though DBS is targeted at one single brain area, its therapeutic effect appears to be due to the modulation of a network, since effects of DBS have been measured in remote brain areas. Figee et al. (2013) showed that DBS targeted at the nucleus accumbens in OCD patients normalized nucleus accumbens activation but as well reduced the pre-treatment increased connectivity between the accumbens and the prefrontal cortex. This reduction in over-connectivity correlates with symptom improvements, empirically supporting the hypothesis that DBS overwrites pathologic network activity. A glucose (PET) study showed a decrease in prefrontal cortex metabolism following DBS of the subthalamic nucleus (Lejeune 2010). Second, modulation of the circuitry results in rapid symptom changes. These changes may be due to alterations in the synchronization dynamics within the frontostriatal network. Smolders et al (2013) have shown that DBS may reduce the phase stability of frontal theta oscillations without affecting theta power. A similar finding has been reported with DBS of the subthalamic nucleus (Bastin 2014). Third, Figee et al. (2014) showed that DBS of the nucleus accumbens induced striatal dopamine release, associated with improved clinical status, suggesting that DBS may compensate for a defective dopaminergic system.

The most obvious difference between invasive neuromodulation by DBS and the non-invasive modulation by rTMS or tDCS, is the primary focus of stimulation. In DBS the subcortical CSTC regions (e.g., the anterior limb of the capsula interna, the ventral capsule/striatum, and the nucleus accumbens) are stimulated, aiming at inhibiting the hyperactivated ventral motivational CSTC circuit. Using rTMS or tDCS, the cortical CSTC regions are targeted, aiming at enhancing the function of the dorsal cognitive CSTC circuit (when targeting the dorsolateral prefrontal cortex) or 
inhibiting the sensorimotor CSTC circuit (by stimulation of the supplementary motor area). In rats DBS in the ventral striatum reduced fear expression and strengthened extinction memory (Rodriquez-Romaguera et al. 2012). Recent work on left dorsolateral prefrontal rTMS versus sham showed that rTMS may modulate automatic emotion regulation capacity by influencing fronto-limbic connectivity (de Wit et al. 2015). In a recent paper on a broad range of psychiatric and neurological disorders, Fox et al. (2014) showed that invasive (e.g., DBS) and non-invasive (e.g., rTMS and tDCS) techniques for neurostimulation, although using different targets for stimulation, in fact target different nodes within the same network. This opens new opportunities to translate knowledge from mechanistic research in DBS to targets for non-invasive neuromodulatory therapies, in this way enabling a partial shift from expensive invasive neurosurgical interventions to cheaper non-invasive treatments in the future (van den Heuvel et al. 2015). The other important difference between DBS and rTMS is the continuous stimulation in DBS versus the temporal stimulation in rTMS or tDCS. Although also in rTMS/tDCS long-lasting effects can be achieved, via long-term potentiation and long-term depression of specific CSTC connections, these techniques should be regarded as adjuvant techniques aiming at the potentiation of the behavioral changes trained during CBT, by enhancing the extinction of conditioned responses, reducing the over-reliance on habitual behaviors, or by improving emotion regulation strategies. In this way it can function as catalyst of a behavioral change. Also for DBS rules that optimal treatment effects are achieved in case of adjuvant CBT (Mantione et al. 2014).

\section{Conclusions and future directions}

As illustrated by this overview the brain circuits involved in compulsivity are plastic, and the findings of neuroimaging studies largely depend on the developmental stage of the subjects included, the stage of disease and presence of chronicity, the actual mental state during data acquisition related to the study design and the condition of the patients, and the effects of experienced past and current treatments.

Since most research used strict age ranges, a gap exists between paediatric and adult studies. Heterogeneity within the disease group is large, due to variation in symptom profile, neurodevelopmental stage, disease stage, and treatment history. Since symptoms often start in childhood and progress towards adulthood, 
in adult studies it is impossible to disentangle the neural correlates implicated in cause and consequence of the disease. Therefore, a lifespan approach is needed to understand how brain changes relate to profile and stage. Insight in the presymptomatic stage of the disease, before the brain has been changed by the disease and treatments, will help to understand how risk confers to disease. The extreme opposite end of the longitudinal design is post-mortem research of the brain from ante-mortem well-characterized patients, including ante- and post-mortem brain imaging. This enables the translation from cellular findings to in vivo-brain imaging characteristics and clinical phenotypes, and stimulates the development of treatment modalities that directly target the underlying cellular mechanisms.

Most literature is based on studies in a mono-diagnostic group of patients versus controls, hampering the study on overlap and differentiation across related disorders. Trans-diagnostic studies need to be a priority. Brain imaging communities in different diseases increasingly start collaborating, aiming to perform meta- and mega-analyses and trans-diagnostic comparisons. A good example is ENIGMA (Enhancing NeuroImaging and Genetics by Meta-Analysis), an unprecedented initiative to pool MRI and genetic data of the major mental disorders, to perform imaging-genetics meta-analyses (Thompson et al. 2014). The overall goal is to unite the imaging and genomics communities to solve biomedical problems that no one group could answer alone, by performing well-powered trans-diagnostic comparisons and by studying general mechanism related to altered brain development across the life span, and under influence of genetic (both risk and protecting factors) and environmental factors (e.g., medication).

The field may benefit from better translation from fundamental studies on brain circuit structure and function to targets for innovative treatments as well as brain-based guidance of clinical practice. After 3 decades of brain imaging research trying to understand disease mechanism at the group level, the field now needs the shift toward prediction of treatment response and disease course prospectively at the individual level. The machine learning approach might help to achieve this goal (Orrù et al. 2015), but so far studies have been small, mainly in depression, and these studies achieved only moderate classification accuracies. Increased classification might be reached by the combined analyses of both clinical characteristics related to disease profile and disease stage, and information from multi-modal brain imaging measurements. However, from a practical and cost-efficiency point of view, 
widespread use of neuroimaging-based prediction markers of treatment response, in case of proven feasibility, necessitates a shift to cheaper and more widely available imaging techniques, such as electroencephalography (EEG), to implement in the clinical setting (van den Heuvel, 2015). 
Figure:

Title: For compulsivity relevant cortico-striato-thalamo-cortical (CSTC) and frontolimbic circuits

Abbreviations:

SMA: supplementary motor area, preSMA: pre-supplementary motor area, dmPFC:

dorsomedial prefrontal cortex, IFG: inferior frontal gyrus, vlPFC: ventrolateral prefrontal cortex, OFC: orbitofrontal cortex, vmPFC: ventromedial prefrontal cortex, pPut: posterior putamen, dCaud: dorsal caudate nucleus, vCaud: ventral caudate nucleus, NAcc: nucleus accumbens, Amygd: amygdala, Tham: thalamus, CSTC: cortico-striato-thalamo-cortical. 


\section{References}

Abler B, Erk S, Walter H. Human reward system activation is modulated by a single dose of olanzapine in healthy subjects in an event-related, double-blind, placebocontrolled fMRI study. Psychopharmacology 2007; 191: 823-33.

Abler B, Grön G, Hartmann A, Metzger C, Walter M. Modulation of frontostriatal interaction aligns with reduced primary reward processing under serotonergic drugs. J Neurosci. 2012; 32: 1329-35.

Adler CM, McDonough-Ryan P, Sax KW, Holland SK, Arndt S, Strakowski SM. fMRI of neuronal activation with symptom provocation in unmedicated patients with obsessive-compulsive disorder. J Psychiatr Res 2000; 34: 317-324.

Admon R, Bleich-Cohen M, Weizmant R, Poyurovsky M, Faragian S, Hendler T. Functional and structural neural indices of risk aversion in obsessive-compulsive disorder (OCD). Psychiatry Res 2012; 203: 207-213.

Albein-Urios N, Verdejo-Román J, Asensio S, Soriano-Mas C, Martínez-González JM, Verdejo-García A. Re-appraisal of negative emotions in cocaine dependence: dysfunctional corticolimbic activation and connectivity. Addiction Biol 2014; 19: $415-426$

Alexander GE, DeLong MR, Strick PL. Parallel organization of functionally segregated circuits linking basal ganglia and cortex. Annu Rev Neurosci. 1986; 9: 357-381.

American Psychiatric Association: Diagnostic and Statistical Manual of Mental Disorders, fifth edition (DSM-5). Washington DC: American Psychiatric Association, 2013.

Apostolova I, Block S, Buchert R, Osen B, Conradi M, Tabrizian S, et al. Effects of behavioral therapy or pharmacotherapy on brain gluocose metabolism in subjects with 
obsessive-compulsive disorder as assessed by brain FDG PET. Psychiatry Research: Neuroimaging 2010; 184: 105-116.

Arce E, Simmons AN, Lovero KN, Stein MB, Paulus MP. Escitalopram effects on insula and amygdala BOLD activation during emotional processing. Psychopharmacology 2008; 196: 661-72.

Arnsten AF, Rubia K. Neurobiological circuits regulating attention, cognitive control, motivation, and emotion: disruptions in neurodevelopmental psychiatric disorders. $\mathrm{J}$ Am Acad Child Adolesc Psychiatry 2012; 51: 356-367.

Ashby FG, Turner BO, Horvitz JC. Cortical and basal ganglia contributions to habit learning and automaticity. Trends Cogn Sci 2010; 14: 208-215.

Banks GP, Mikell CB, Youngerman BE, Henriques B, Kelly KM, Chan AK, Herrera D, Dougherty DD, Eskandar EN, Sheth SA. Neuroanatomical characteristics associated with response to dorsal anterior cingulotomy for obsessive-compulsive disorder. JAMA Psychiatry 2014; 72: 127-35.

Ball TM, Ramsawh HJ, Campbell-Sills L, Paulus MP, Stein MB. Prefrontal dysfunction during emotion regulation in generalized anxiety and panic disorders. Psychol Med 2012; 43: 1475-1486.

Balleine BW. Neural bases of food-seeking: affect, arousal and reward in corticostriatolimbic circuits. Physiol Behav 2005; 86: 717-730.

Bari A, Robbins TW. Inhibition and impulsivity: behavioral and neural basis of response control. Prog Neurobiol 2013; 108: 44-79.

Bastin J, Polosan M, Piallat B, Krack P, Bougerol T, Chabardès S, David O. Changes of oscillatory activity in the subthalamic nucleus during obsessive-compulsive disorder symptoms: Two case reports. Cortex 2014; 60: 145-50. 
Baxter Jr LR, Schwartz JM, Bergman KS, Szuba MP, Guze BH, Mazziotta JC et al. Caudate glucose metabolic rate changes with both drug and behavior therapy for obsessive-compulsive disorder. Arch Gen Psychiatry 1992; 49: 681-689.

Belin D, Mar AC, Dalley JW, Robbins TW, Everitt BJ. High impulsivity predicts the switch to compulsive cocaine-taking. Science 2009; 320: 1352-1355.

Belin D, Jonkman S, Dickinson A, Robbins TW, Everitt BJ. Parallel and interactive learning within the basal ganglia: relevance for the understanding of addiction. Behav Brain Res 2009; 199: 89-102.

Benazon NR, Moore GJ, Rosenberg DR. Neurochemical analyses in pediatric obsessive-compulsive disorder in patients treated with cognitive-behavioral therapy. J Am Acad Child Adolesc Psychiatry 2003; 42: 1279-1285.

Breiter HC, Rauch SL, Kwong KK, Baker JR, Weiskoff RM, Kennedy DN, Kendrick AD, Davis TL, Jiang A, Cohen MS, Stern CE, Belliveau JW, Baer L, O’Sullivan RL, Savage CR, Jenike MA, Rosen BR. Functional magnetic resonance imaging of symptom provocation in obsessive-compulsive disorder. Arch Gen Psychiatry 1996; 53:595-606.

Britton JC, Stewart SE, Killgore WD, Rosso IM, Price LM, Gold AL, Pine DS, Wilhelm S, Jenike MA, Rauch SL. Amygdala activation in response to facial expressions in pediatric obsessive-compulsive disorder. Depress Anxiety 2010; 27: 643-651.

Brody AL, Saxena S, Schwartz JM, Stoessel P, Maidment K, Phelps E, et al. FDGPET predictors of response to behavioral therapy and pharmacotherapy in obsessivecompulsive disorder. Psychiatry Res NI 1998; 84: 1-6.

Buchsbaum MS, Hollander E, Pallanti S, Baldini Rossi N, Platholi J, Newmark R, Bloom R, Sood E. Positron emission tomography imaging of risperidone augmentation in serotonin reuptake inhibitor-refractory patients. Neuropsychobiology 2006; 53: 157-68. 
Bullmore E, Sporns O. Complex brain networks: graph theoretical analysis of structural and functional systems. Nat Rev Neurosci 2009; 10: 186-98.

Bullmore E, Sporns O. The economy of brain network organization. Nat Rev Neurosci 2012; 13: 336-49.

Cannistraro PA, Wright CI, Wedig MM, Martis B, Shin LM, Wilhelm S, Rauch SL. Amygdala responses to human faces in obsessive-compulsive disorder. Biol Psychiatry 2004; 56: 916-920.

Cardinal RN, Parkinson JA, Hall J, Everitt BJ. Emotion and motivation: the role of the amygdala, ventral striatum, and prefrontal cortex. Neurosci Biobehav Rev 2002; 26: $321-352$.

Cardoner N, Harrison BJ, Pujol J, Soriano-Mas C, Hernandez-Ribas R, Lopez-Sola M, Real E, Deus J, Ortiz H, Alonso P, Menchon JM. Enhanced brain responsiveness during active emotional face processing in obsessive-compulsive disorder. World $\mathbf{J}$ Biol Psychiatry 2011; 12: 349-363.

Chamberlain SR, Fineberg NA, Menzies LA, Blackwell AD, Bullmore ET, Robbins TW, Sahakian BJ. Impaired cognitive flexibility and motor inhibition in unaffected first-degree relatives of patients with obsessive-compulsive disorder. Am J Psychiatry 2007; 164: 335-338.

Chamberlain SR, Menzies L, Hampshire A, Suckling J, Fineberh NA, del Campo N, Aitken M, Craig K, Owen AM, Bullmore ET, Robbins TW, Sahakian BJ.

Orbitofrontal dysfunction in patients with obsessive-compulsive disorder and their unaffected relatives. Science 2008; 321: 421-2.

Chamberlain SR, Odlaug BL, Boulougouris V, Fineberg NA, Grant JE.

Trichotillomania: neurobiology and treatment. Neurosci Biobehav Rev 2009; 33: 83142. 
Chambers CD, Garavan H, Bellgrove MA. Insights into the neural basis of response inhibition from cognitive and clinical neuroscience. Neurosci Biobehav Rev 2009; 33: 631-646.

Cho YT, Ernst M, Fudge JL. Cortico-amygdala-striatal circuits are organized as hierarchical subsystems through the primate amygdala. J Neurosci 2013; 33: 14017 14030.

Clark DA, Beck AT. Cognitive theory and therapy of anxiety and depression: convergence with neurobiological findings. Trends Cogn Sci 2010; 14: 418-424.

Colibazzi T, Zhu H, Bansal R, Schultz RT, Wang Z, Peterson BS. Latent volumetric structure of the human brain: exploratory factor analysis and structural equation modeling of gray matter volumes in healthy children and adults. Hum Brain Mapp 2008; 29: 1302-1312.

Cummings JL. Frontal-subcortical circuits and human behavior. Arch Neurol 1993; 50: $873-880$

Dalley JW, Fryer TD, Brichard L, Robinson ES, Theobald DE, Laane K, Pena Y, Murphy ER, Shah Y, Probst K, Abakumova I, Aigbirhio FI, Richards HK, Hong Y, Baron JC, Everitt BJ, Robbins TW. Nucleus accumbens D2/3 receptors predict trait impulsivity and cocaine reinforcement. Science 2007; 315: 1267-70.

Davis M, Whalen PJ. The amygdala: vigilance and emotion. Mol Psychiatry 2001; 6: $13-34$.

de Almeida JR, Phillips ML, Cerqueira CT, Zilberman M, Lobo D, Henna E, Tavares H, Amaro E, Gorenstein C, Gentil V, Busatto GF. Neural activity changes to emotional stimuli in healthy individuals under chronic use of clomipramine. J Psychopharmacol 2010; 24: 1165-74. 
Delgado MR, Olsson A, Phelps EA. Extending animal models of fear conditioning to humans. Biol Psychol 2006; 73: 39-48.

de Vries FE, de Wit SJ, Cath DC, van der Werf YD, van der Borden V, van Rossum TB, van Balkom AJ, van der Wee NJ, Veltman DJ, van den Heuvel OA.

Compensatory frontoparietal activity during working memory: an endophenotype of obsessive-compulsive disorder. Biol Psychiatry 2014; 76: 878-887.

de Wit SJ, de Vries FE, van der Werf YD, Cath DC, Heslenfeld DJ, Veltman EM, van Balkom AJLM, Veltman DJ, van den Heuvel OA. Pre-supplementary motor area hyperactivity during response inhibition: a candidate endophenotype of obsessivecompulsive disorder. Am J Psychiatry 2012; 169: 1100-1108.

de Wit SJ, Alonso P, Schweren L, Mataix-Cols D, Lochner C, Menchon JM, Stein DJ, Fouche JP, Soriano-Mas C, Sato JR, Hoexter MQ, Denys D, Nakamae T, Nishida S, Kwon JS, Jang JH, Busatto GF, Cardoner N, Cath DC, Fukui K, Jung WH, Kim SN, Miguel EC, Narumoto J, Phillips ML Pujol J, Remijnse PL, Sakai Y, Shin NY, Yamada K, Veltman DJ, van den Heuvel OA. Voxel-based morphometry multi-center mega-analysis of structural brain scans in obsessive-compulsive disorder. Am J Psychiatry 2014; 169: 1100-8.

de Wit SJ, van der Werf YD, Mataix-Cols D, Trujillo J, van Oppen P, Veltman DJ, van den Heuvel OA. Emotion regulation before and after transcranial magnetic stimulation in obsessive-compulsive disorder. Psychol Med 2015; in press.

Donders FC. On the speed of mental processes. Acta Psychol 1969; 30: 412-431.

Egbert MD, Barandiaran XE. Modeling habits as self-sustaining patterns of sensorimotor behavior. Frontiers Hum Neurosci 2014; 8: 590, doi: 10.3389/fnhum.2014.00519.

Erk S, Mikschl A, Stier S, Ciaramidaro A, Gapp V, Weber B et al. Acute and sustained effects of cognitive emotion regulation in major depression. J Neurosci 2010; 30: 15726-15734. 
Etkin A, Wager TD. Functional neuroimaging of anxiety: a meta-analysis of emotional processing in PTSD, social anxiety disorder, and specific phobia. Am J Psychiatry 2007; 164: 1476-1488.

Everitt BJ, Robbins TW. Neural systems of reinforcement for drug addiction: from actions to habits to compulsion. Nature Neuroscience 2005; 8: 1481-1489.

Fan Q, Yan X, Wang J, Chen Y, Wang X, Li C, Tan L, You C, Zhang T, Zuo S, Xu D, Chen K, Finlayson-Burden JM, Xiao Z. Abnormalities of white matter microstructure in unmedicated obsessive-compulsive disorder and changes after medication. PLoS One 2012; 7: e35889.

Figee M, Luigjes J, Smolders R, Valencia-Alfonso CE, van Wingen G, de Kwaasteniet B, Mantione M, Ooms P, de Koning P, Vulink N, Levar N, Droge L, van den Munckhof P, Schuurman PR, Nederveen A, van den Brink W, Mazaheri A, Vink M, Denys D. Deep brain stimulation restores frontostriatal network activity in obsessive-compulsive disorder. Nat Neurosci 2013; 16: 386-387.

Figee M, de Koning P, Klaassen S, Vulink N, Mantione M, van den Munckhof P, Schuurman R, van Wingen G, van Amelsvoort T, Booij J, Denys D. Deep brain stimulation induces striatal dopamine release in obsessive-compulsive disorder. Biol Psychiatry 2014; 75: 647-652.

Fineberg NA, Chamberlain SR, Goudriaan AE, Stein DJ, Vanderschuren LJ, Gillan CM, Shekar S, Gorwood PA, Voon V, Morein-Zamir S, Denys D, Sahakian BJ, Moeller FG, Robbins TW, Potenza MN. New developments in human neurocognition: clinical, genetic, and brain imaging correlates of impulsivity and compulsivity. CNS Spectrums 2014; 19: 69-89.

Fox HC, Axelrod SR, Paliwal P, Sleeper J, Sinha R. Difficulties in emotion regulation and impulse control during cocaine abstinence. Drug Alcohol Depend 2007; 89: 298301. 
Fox MD, Buckner RL, Liu H, Chakravarty MM, Lozano AM, Pascual-Leone A. Resting-state networks link invasive and noninvasive brain stimulation across diverse psychiatric and neurological disease. Proc Natl Acad Sci USA 2014; 111: E4367-75.

Freyer T, Klöppel S, Tüscher O, Kordon A, Zurowski B, Kuelz AK, et al. Frontostriatal activation in patients with obsessive-compulsive disorder before and after cognitive behavioral therapy. Psychol Med 2011; 41: 207-216.

Friston KJ, Buechel C, Fink GR, Morris J, Rolls E, Dolan RJ. Psychophysiological and modulatory interactions in neuroimaging. Neuroimage 1997; 6: 218-29.

Friston KJ, Harrison L, Penny W. Dynamic causal modelling. Neuroimage 2003; 19 : 1273-302.

Fullana MA, Cardoner N, Alonso O, Subirà M, López-Solà C, Pujol J, et al. Brain regions related to fear extinction in obsessive-compulsive disorder and its relation to exposure therapy outcome: a morphometric study. Psychol Med 2014; 44: 845-856.

Geller DA, Biederman J, Griffin S, Jones J, Lefkowitz TR. Comorbidity of juvenile obsessive-compulsive disorder with disruptive behavior disorders. J Am Acad Child Adolesc Psychiatry 1996; 35: 1637-1646.

Gevins A, Cutillo B. Spatiotemporal dynamics of component processes in human working memory. Electroencephalogr Clin Neurophysiol 1993; 87: 128-143.

Gilbert AR, Moore GJ, Keshavan MS, Paulson LA, Narula V, Mac Master FP, Stewart CM, Rosenberg DR. Decrease in thalamic volumes of pediatric patients with obsessive-compulsive disorder who are taking paroxetine. Arch Gen Psychiatry 2000 May; 57: 449-56.

Gillan CM, Robbins TW, van Wingen G, Sahakian BJ, van den Heuvel OA. The role of habit in compulsivity. Eur Neuropsychopharm 2015 (this volume) 
Gillan CM, Apergis-Schoute A, Morein-Zamir S, Urcelay GP, Sule A, Fineberg NA, Sahakian BJ, Robbins TW. Functional neuroimaging of avoidance habits in obsessive-compulsive disorder. Am J Psychiatry 2015; 172: 284-93.

Gogtay N, Giedd JN, Lusk L, Hayashi KM, Greenstein D, Vaituzis AC, Nugent TF, Herman DH, Clasen LS, Toga AW, Rapoport JL, Thompson PM. Dynamic mapping of human cortical development during childhood through early adulthood. Proc Natl Acad Sci USA 2004; 101: 8174-8179.

Goodwin H, Haycraft E, Meyer C. Emotion regulation styles as longitudinal predictors of compulsive exercise: a twelve month prospective study. J Adolesc 2014; 37: 1399-1404.

Gottlich M, Kramer UM, Kordon A, Hohagen F, Zurowski B. Decreased limbic and increased fronto-parietal connectivity in unmedicated patients with obsessivecompulsive disorder. Hum Brain Mapp 2014; 35: 5617-5632.

Graybiel AM, Rauch SL. Toward a neurobiology of obsessive-compulsive disorder. Neuron 2000; 28: 343-347.

Groenewegen HJ, Uylings HB. The prefrontal cortex and the integration of sensory, limbic and autonomic information. Prog Brain Res 2000; 126: 3-28.

Groenewegen HJ, van den Heuvel OA, Cath DC, Voorn P, Veltman DJ. Does an imbalance between the dorsal and ventral striatopallidal systems play a role in Tourette's syndrome? A neuronal circuit approach. Brain \& Development 2003; 25 (Suppl 1): S3-14.

Gross JJ. Emotion regulation: Taking stock and moving forward. Emotion 2013; 13: 359.

Haber SN, Knutson B. The reward circuit: linking primate anatomy and human imaging. Neuropsychopharmacology 2010; 35: 4-26. 
Harmer CJ, Cowen PJ. 'It's the way that you look at it'--a cognitive neuropsychological account of SSRI action in depression. Philos Trans R Soc Lond B Biol Sci. 2013; 368: 20120407.

Harrison BJ, Soriano-Mas C, Pujol J, Ortiz H, Lopez-Sola M, Hernandez-Ribas R, Deus J, Alonso P, Yucel M, Pantelis C, Menchon JM, Cardoner N. Arch Gen Psychiatry 2009; 66: 1189-1200.

Harrison BJ, Pujol J, Cardoner N, Deus J, Alonso P, Lopez-Sola M, ContrerasRodriquez O, Real E, Segalas C, Blanco-Hinojo L, Menchon JM, Soriano-Mas C. Brain conrticostriatal systems and the major clinical symptom dimensions of obsessive-compulsive disorder. Biol Psychiatry 2013; 73: 321-328.

Hashimoto N, Nakaaki S, Kawaguchi A, Sato J, Kasai H, Nakamae T, et al. Brain structural abnormalities in behavior therapy-resistant obsessive-compulsive disorder revealed by voxel-based morphometry. Neuropsychiatric Disease and Treatment 2014; 10: 1987-1996

Ho Pian KL, van Megen HJ, Ramsey NF, Mandl R, van Rijk PP, Wynne HJ, Westenberg HG. Decreased thalamic blood flow in obsessive-compulsive disorder patients responding to fluvoxamine. Psychiatry Res. 2005; 138: 89-97.

Hoexter MQ, Dougherty DD, Shavitt RG, D’Alcante CC, Duran FLS, Lopes AC, et al. Differential prefrontal gray matter correlates of treatment response to fluoxetine or cognitive-behavioral therapy in obsessive-compulsive disorder. Eur Neuropsychopharmacol 2013; 23: 569-80.

Hoexter MQ, de Souza Duran FL, D'Alcante CC, Dougherty DD, Shavitt RG, Lopes AC, Diniz JB, Deckersbach T, Batistuzzo MC, Bressan RA, Miguel EC, Busatto GF. Gray matter volumes in obsessive-compulsive disorder before and after fluoxetine or cognitive-behavior therapy: a randomized clinical trial. Neuropsychopharmacology 2012; 37: 734-45. 
Hornak J, O’Doherty J, Bramham J, Rolls ET, Bullock PR, Polkey CE. Rewardrelated reversal learning alter surgical excisions in orbitofrontal or dorsolateral prefrontal cortex in humans. J Cogn Neurosci 2004; 16: 463-378.

Huyser C, van den Heuvel O, Wolters LH, de Haan E, Boer F, Veltman DJ. Increased orbital frontal gray matter volume after cognitive behavioral therapy in paediatric obsessive compulsive disorder. World J Biol Psychiatry 2013; 14: 319-31

Huyser C, van den Heuvel OA, Wolters L, de Haan E, Lindauer R, Veltman DJ. A longitudinal VBM study in paediatric obsessive-compulsive disorder at 2-year followup after cognitive behavioral therapy. World J Biol Psychiatry 2014; 15: 443-452

Huyser C, Veltman DJ, Wolters LH, de Haan E, Boer F. Functional magnetic resonance imaging during planning before and after cognitive-behavioral therapy in pediatric obsessive-compulsive disorder. J Am Acad Child Adolesc Psychiatry 2010; 49: $1238-1248$.

Huyser C, Veltman DJ, Wolters LH, de Haan E, Boer F. Developmental aspects of error and high-conflict related brain activity in pediàtric obsessive-compulsive disorder: a fMRI study with a Flanker task before and after CBT. J Child Psychol Psychiatry 2011; 52: 1251-1260

Jaafari N, Rachid F, Ritge JY, Polosan, El-Hage W, Belin D, Vibert N, Pelissolo A. Safety and efficacy of repetitive transcranial magnetic stimulation in the treatment of obsessive-compulsive disorder: a review. World J Biol Psychiatry 13: 164-177.

Jacobs ML, Morelen D, Suveg C, Brown Jacobsen AM, Whiteside SP. Emotional, behavioral, and cognitive factors that differentiate obsessive-compulsive disorder and other anxiety disorders in youth. Anxiety Stress Coping 2012; 25: 229-237.

Jang JH, Kwon JS, Jang DP, Moon WJ, Lee JM, Ha TH, Chung EC, Kim IY, Kim SI. A proton MRSI study of brain $\mathrm{N}$-acetylaspartate level after 12 weeks of citalopram treatment in drug-naive patients with obsessive-compulsive disorder. Am J Psychiatry 2006; 163: 1202-7. 
Jung WH, Kang DH, Kim E, Shin KS, Jang JH, Kwon JS. Abnormal corticostriatallimbic functional connectivity in obsessive-compulsive disorder during reward processing and resting-state. NeuroImage Clinical 2013; 3: 27-38.

Kisely S, Hall K, Siskind D, Frater J, Olson S, Crompton D. Deep brain simulation for obsessive-compulsive disorder: a systematic review and meta-analysis. Psychol Med 2014; 44: 3533-3542.

Kraus C, Ganger S, Losak J, Hahn A, Savli M, Kranz GS, Baldinger P, Windischberger C, Kasper S, Lanzenberger R. Gray matter and intrinsic network changes in the posterior cingulate cortex after selective serotonin reuptake inhibitor intake. NeuroImage 2014; 84: 236-44.

Lázaro L, Caldú X, Junqué C, Bargalló N, Andrés S, Morer A, Castro-Fornieles J. Cerebral activation in children and adolescents with obsessive-compulsive disorder before and after treatment: a functional MRI study. J Psychiatr Res 2008; 42: 1051-9.

Lázaro L, Bargalló N, Castro-Fornieles J, Falcón C, Andrés S, Calvo R, et al. Brain changes in children and adolescents with obsessive-compulsive disorder before and after treatment: A voxel-based morphometric MRI study. Psychiatry Research: Neuroimaging 2009; 172: 140-146

Lefaucheur JP, André-Obadia N, Antal A, Ayache SS, Baeken C, Benninger DH, Cantello RM, Cincotta M, de Carvalho M, De Ridder D, Devanne H, Di Lazzaro V, Filipović SR, Hummel FC, Jääskeläinen SK, Kimiskidis VK, Koch G, Langguth B, Nyffeler T, Oliviero A, Padberg F, Poulet E, Rossi S, Rossini PM, Rothwell JC, Schönfeldt-Lecuona C, Siebner HR, Slotema CW, Stagg CJ, Valls-Sole J, Ziemann U, Paulus W, Garcia-Larrea L. Evidence-based guidelines on the therapeutic use of repetitive transcranial magnetic stimulation (rTMS). Clin Neurophysiol. 2014; 125 : 2150-2206.

Le Jeune F, Vérin M, N'Diaye K, Drapier D, Leray E, Du Montcel ST, Baup N, Pelissolo A, Polosan M, Mallet L, Yelnik J, Devaux B, Fontaine D, Chereau I, 
Bourguignon A, Peron J, Sauleau P, Raoul S, Garin E, Krebs MO, Jaafari N, Millet B Decrease of prefrontal metabolism after subthalamic stimulation in obsessivecompulsive disorder: a positron emission tomography study. Biol Psychiatry. 2010; 68(11): 1016-22.

Linden DEJ. How psychotheapy changes the brain- the contribution of functional neuroimaging. Mol Psychiatry 2006; 11: 528-538

Logan GD. On the ability to inhibit thougt and action: a user's guide to the stop signal paradigm. In: Inhibitory processes in attention, memory, and language. Eds: Dagenbach D, Carr TH (San Diego, CA, Academic Press), p 189-239.

Lopes AC, Greenberg BD, Canteras MM, Batistuzzo MC, Hoexter MQ, Gentil AF, Pereira CA, Joaquim MA, de Mathis ME, D'Alcante CC, Taub A, de Castro DG, Tokeshi L, Sampaio LA, Leite CC, Shavitt RG, Diniz JB, Busatto G, Norén G, Rasmussen SA, Miguel EC. Gamma ventral capsulotomy for obsessive-compulsive disorder: a randomized clinical trial. JAMA Psychiatry 2014; 71: 1066-1076.

Ma N, Liu Y, Li N, Wang CK, Zhang H, Jiang XF, Xu HS, Fu XM, Hu X, Zhang DR. Addiction related alterations in resting-state brain connectivity. NeuroImage 2010; 49: $738-744$.

MacLean PD. Psychosomatic disease and the visceral brain; recent developments bearing on the Papez theory of emotion. Psychosom Med 1949; 11: 338-353.

Mantione M, Nieman DH, Figee M, Denys D. Cognitive-behavioral therapy augments the effects of deep brain stimulation in obsessive-compulsive disorder. Psychol Med 2014; 44: 3515-3522.

Mataix-Cols D, van den Heuvel OA. Common and distinct neural correlates of obessive-compulsive and related disorders. Psychiatr Clin North Am 2006; 29: 391410. 
McCabe C, Mishor Z, Cowen PJ, Harmer CJ. Diminished Neural Processing of Aversive and Rewarding Stimuli During Selective Serotonin Reuptake Inhibitor Treatment. Biol Psychiatry 2010; 67: 439-45.

McCabe C, Mishor Z, Filippini N, Cowen PJ, Taylor MJ, Harmer CJ. SSRI administration reduces resting state functional connectivity in dorso-medial prefrontal cortex. Mol Psychiatry 2011; 16: 592-4.

McCabe C, Huber A, Harmer CJ, Cowen PJ. The D2 antagonist sulpiride modulates the neural processing of both rewarding and aversive stimuli in healthy volunteers. Psychopharmacology 2011; 217: 271-8.

Menzies L, Achard S, Chamberlain SR, Fineberg NA, Chen Ch, del Campo N, Sahakian BJ, Robbins TW, Bullmore TE. Neurocognitive endophenotypes of obsessive-compulsive disorder. Brain 2007; 130: 3223-3236.

Menzies L, Chamberlain SR, Laird AR, Thelen SM, Sahakian BJ, Bullmore ET. Integrating evidence from neuroimaging and neuropsychological studies of obsessivecompulsive disorder: the orbitofronto-striatal model revisited. Neurosci Biobehav Rev 2008; 32: 525-549.

Milad MR, Rauch SL. Obsessive-compulsive disorder: beyond segregated corticostriatal pathways. Trends Cogn Sci 2012; 16: 43-51.

Montigny C, Castellanos-Ryan N, Whelan R, Banaschewski T, Barker GJ, Buchel C, Gallinat J, Flor H, Mann K, Paillere-Martinot ML, Nees F, Lathrop M, Loth E, Paus T, Pausova Z, Rietschel M, Schumann G, Smolka MN, Struve M, Robbins TW, Garavan H, Conrod PJ, IMGEN Consortium. A phenotypic structure and neural correlates of compulsive behaviors in adolescents. PLos One 2013; 8: e80151, doi: 10.1371/journal.pone.0080151.

Morgiève M, N'Diaye K, Haynes WIA, Granger B, Clair AH, Pelissolo A, et al. Dynamics of psychotherapy-related cerebral haemodynamic changes in obsessive- 
compulsive disorder using a personalized exposure task in functional magnetic resonance imaging. Psychological Medicine 2014; 44: 1461-1473

Milad MR, Rauch SL. Obsessive-compulsive disorder: beyond segregated corticostriatal pathways. Trends Cogn Neurosci 2012; 16: 43-51

Murray JE, Dilleen R, Pelloux Y, Economidou D, Dalley JW, Belin D, Everitt BJ. Increased impulsivity retards the transition to dorsolateral striatal dopamine control of cocaine seeking. Biol Psychiatry 2014; 76: 15-22.

Nabeyama M, Nakagawa A, Yoshiura T, Nakao T, Nakatani E, Togao O, et al. Functional MRI study of brain activation alterations in patients with obsessivecompulsive disorder after symptom improvement. Psychiatry Research:

Neuroimaging 2008; 236-247

Nakao T, Nakagawa A, Yoshiura T, Nakatani E, Nabeyama M, Yoshizato C, et al. Brain activation of patients with Obsessive-Compulsive Disorder during neuropsychological and symptom provocation tasks before and after symptom improvement: a functional magnetic resonance imaging study. Biol Psychiatry 2005; 57: $901-10$.

Nakatani E, Nakgawa A, Ohara Y, Goto S, Uozumi N, iwakiri M et al. Effects of behavior therapy on regional cerebral blood fow in obsessive-compulsive disorder. Psychiatry Res 2003; 124: 113-120

Nuttin B, Wu H, Mayberg H, Hariz M, Gabriëls L, Galert T, Merkel R, Kubu C, Vilela-Filho O, Matthews K, Taira T, Lozano AM, Schechtmann G, Doshi P, Broggi G, Régis J, Alkhani A, Sun B, Eljamel S, Schulder M, Kaplitt M, Eskandar E, Rezai A, Krauss JK, Hilven P, Schuurman R, Ruiz P, Chang JW, Cosyns P, Lipsman N, Voges J, Cosgrove R, Li Y, Schlaepfer T. Consensus on guidelines for stereotactic neurosurgery for psychiatric disorders. J Neurol Neurosurg Psychiatry 2014; 85:10038. 
Ochsner KN, Bunge SA, Gross JJ, Gabrieli JDE. Rethinking Feelings: An fMRI Study of the Cognitive Regulation of Emotion. Journal of Cognitive Neuroscience 2002; 14: 1215-1229.

Ochsner KN, Ray RD, Cooper JC, Robertson ER, Chopra S, Gabrieli JD, Gross JJ. For better or for worse: neural systems supporting the cognitive down and upregulation of negative emotion. NeuroImage 2004; 23: 483-99.

Ochsner KN, Gross JJ. The cognitive control of emotion. Trends in Cognitive Sciences 2005; 9: 242-249.

O'Doherty J, Kringelbach ML, Rolls ET, Hornak J, Andrews C. Abstract reward and punishment representations in the human orbitofrontal cortex. Nat Neurosci 2001; 4: 95-102.

Olantuji BO, Ferreira-García R, Caseras X, Fullana MA, Wooderson S, Speckens A, et al. Predicting response to cognitive behavioral therapy in contamination-based obsessive-compulsive disorder from funcional magnetic resonance imaging. Pychological Medicine 2014; 44: 2125-2137

O’Neill J, Piacentini JC, Chang S, Levitt JG, Rozenman M, Bergman L, et al. MRSI correlates of cognitive-behavioral therapy in pediatric obsessive-compulsive disorder. Progr Neuro-Psychopharmacol Biol Psychiatry 2012; 36: 161-168

Orru G, Pettersson-Yeo W, Marquand AF, Sartori G, Mechelli A. Using support vector machine to identify imaging biomarkers of neurological and psychiatric disease: a critical review. Neurosci Biobehav Rev 2012; 36: 1140-1152.

Ossewaarde L, Verkes RJ, Hermans EJ, Kooijman SC, Urner M, Tendolkar I, van Wingen GA, Fernandez G. Two-week administration of the combined serotoninnordrenaline reuptake inhibitor duloxetine augments functioning of medolimbic incentive processing circuits. Biol Psychiatry 2011; 70: 568-574. 
Outhred T, Hawkshead BE, Wager TD, Das P, Malhi GS, Kemp AH. Acute neural effects of selective serotonin reuptake inhibitors versus noradrenaline reuptake inhibitors on emotion processing: Implications for differential treatment efficacy. Neurosci Biobehav Rev 2013; 37: 1786-800.

Perlman SB, Pelphry KA. Regulatory brain development: balancing emotion and cognition. Soc Neurosci 2010; 5: 533-542.

Perlman SB, Pelphry KA. Developing connections for affective regulation: agerelated changes in emotional brain connectivity. J Exp Child Psychol 2011; 108: 607620.

Perry DC, Whitwell JL, Boeve BF, Pankratz VS, Knopman DS, Petersen RC, Jack $\mathrm{CR}$, Josephs KA. Voxel-based morphometry in patients with obsessive-compulsive behaviors in behavioral variant frontotemporal dementia. Eur J Neurol 2012; 19: 911 917.

Piray P, Keramati MM, Dezfouli A, Lucas C, Mokri A. Individual differences in nucleus accumbens dopamine receptors predict development of addiction-like behavior: a computational approach. Neural Comput 2010; 22: 2334-2368.

Phillips ML, Drevets WC, Rauch SL, Lane R. Neurobiology of emotion perception I: the neural basis of normal emotion perception. Biol Psychiatry 2003; 54: 504-514.

Phillips ML, Drevets WC, Rauch SL, Lane R. Neurobiology of emotion perception II: implications for major psychiatric disorders. Biol Psychiatry 2003; 54: 515-528.

Pujol J, Soriano-Mas C, Alonso P, Cardoner N, Menchon JM, Deus J, Vallejo J. Mapping structural brain alterations in obsessive-compulsive disorder. Arch Gen Psychiatry 2004; 61: 720-730.

Ravizza SM, Carter CS. Shifting set about task switching: behavioral and neural evidence for distinct forms of cognitive flexibility. Neuropsychologia 2008; 46: 29242935. 
Remijnse PL, Nielen MM, van Balkom AJ, Cath DC, van Oppen P, Uylings HB, Veltman DJ. Reduced orbitofrontal-striatal activity on a reversal learning task in obsessive-compulsive disorder. Arch Gen Psychiatry 2006; 63: 1225-1236.

Remijnse PL, van den Heuvel OA, Nielen MM, Vriend C, Hendriks GJ, Hoogendijk WJ, Uylings HB, Veltman DJ. Cognitive inflexibility in obsessive-compulsive disorder and major depression in associated with distinct neural correlates. PLos One 2013; 8: 259600. Doi: 10.1371/journal.pone.0059600.

Rive MM, Mockting RJ, Koeter MW, van Wingen G, de Wit SJ, van den Heuvel OA, Veltman DJ, Ruhé HG, Schene A. State dependent differences in emotion regulation between unmedicated bipolar and major depressive disorder. JAMA Psychiatry 2015; 72: 687-96.

Rodriquez-Romaguera J, Do Monte FH, Quirk GJ. Deep brain stimulation of the ventral striatum enhances extinction of conditioned fear. Proc Natl Acad Sci USA 2012; 109: 8764-8769.

Rosenberg DR, Benazon NR, Gilbert A, Sullivan A, Moore GJ. Thalamic volume in pediatric obsessive-compulsive disorder patients before and after Cognitive Behavioral Therapy. Biol Psychiatry 2000; 48:294-300

Rosenberg DR, MacMaster FP, Keshavan MS, Fitzgerald KD, Stewart CM, Moore GJ. Decrease in caudate glutamatergic concentrations in pediatric obsessivecompulsive disorder patients taking paroxetine. J Am Acad Child Adolesc Psychiatry 2000; 39: 1096-1103

Rotge JY, Guehl D, Dilharreguy B, Cuny E, Tignol J, Bioulac B, Allard M, Burbaud P, Aouizerate B. Provocation of obsessive-compulsive symptoms: a quatitative voxelbased meta-analysis of functional neuroimaging studies. J Psychiatry Neurosci 2008; 33: 405-412. 
Rück C, Karlsson A, Steel D, Edman G, Meyerson BA, Ericson K, Nyman H, Asberg M, Svanborg P. Capsulotomy for obsessive-compulsive disorder: long-term follow-up of 25 patients. Arch Gen Psychiatry 2008; 65: 914-922.

Saxena S, Gorbis E, O’Neill JO, Baker SK, Mandelkern MA, Maidment KM, et al. Rapid effects of brief intensive cognitive-behavioral therapy on brain glucose metabolism in obsessive-compulsive disorder. Mol Psychiatry 2009; 14: 197-205

Schwartz JM, Stoessel PW, Baxter Jr LR, Martin KM, Phelps ME. Systematic changes in cerebral glucose metabolic rate after succesful behavior modification treatment of obsessive-compulsive disorder. Arch Gen Psychiatry 1996; 53:109-113

Sebastian A, Pohl MF, Kloppel S, Feige B, Lange T, Stahl C, Voss A, Klauer KC, Lieb K, Tuscher O. Disentangling common and distinct neural subprocesses of response inhibition. NeuroImage 2013a; 64: 601-615.

Sebastian A, Baldermann C, Feige B, Katzev M, Scheller E Helwig B, Lieb K, Weiller C, Tuscher O, Kloppel S. Differential effects of age on subcomponents of response inhibition. Neurobiol Aging 2013b; 34: 2183-2193.

Shallice T. Specific impairments of planning. Philos Trans R Soc Lond B Biol Sci 1982; 298: 199-209.

Shin DJ, Jung WH, He Y, Wang J, Shim G, Byun MS, Jang JH, Kim SN, Lee TY, Park HY, Kwon JS. The effects of pharmacological treatment on functional brain connectome in obsessive-compulsive disorder. Biol Psychiatry 2014; 75: 606-14.

Simon D, Adler N, Kaufmann C, Kathmann N. Amygdala hyperactivation during symptom provocation in obsessive-compulsive disorder and its modulation by distraction. NeuroImage Clinical 2014; 4: 549-557.

Simon D, Kaufmann C, Musch K, Kischkel E, Kathmann N. Fronto-striato-limbic hyperactivation in obsessive-compulsive disorder during individually tailored symptom provocation. Psychophysiology 2010; 47: 728-738. 
Sjoerds Z, de Wit S, van den Brink W, Beekman AJ, Penninx BW, Veltman DJ. Behavioral and neuroimaging evidence for overreliance on habit learning in alcoholdependent patients. Translational Psychiatry 2013; 3: e337.

Slutske WS, Moffit TE, Poulton R, Caspi A. Undercontrolled temperament at age 3 predicts disordered gambling at age 32: a longitudinal study of a complete birth cohort. Psychol Sci 2012; 23: 510-516.

Stephan KE. On the role of general system theory for functional neuroimaging. Journal of Anatomy 2004; 205: 443-70.

Stevens L, Verdejo-Garcia A, Goudriaan AE, Roeyers H, Dom G, Vanderplasschen W. Impulsivity as a vulnerability factor for poor addiction treatment outcomes: a review of neurocognitive findings among individuals with substance use disorders. Journal of Substance Abuse Treatment 2014; 47: 58-72.

Szeszko PR, MacMillan S, McMeniman M, Lorch E, Madden R, Ivey J, Banerjee SP, Moore GJ, Rosenberg DR. Amygdala volume reductions in pediatric patients with obsessive-compulsive disorder treated with paroxetine: preliminary findings.

Neuropsychopharmacology 2004; 29: 826-32.

Tendolkar I, van Wingen G, Urner M, Verkes RJ, Fernandez G. Short-term duloxetine administration affects neural correlates of mood-congruent memory. Neuropsychopharmacology 2011; 36: 2266-2275.

Thompson PM, Stein JL, Medland SE, Hibar DP, et al. The ENIGMA Consortium: large-scale collaborative analyses of neuroimaging and genetic data. Brain Imaging Behav 2014; 8: 153-82.

Thorn CA, Atallah H, Howe M, Graybiel AM. Differential dynamics of activity changes in dorsolateral and dorsomedial striatal loops during learning. Neuron 2010; 66: 781-95. 
Ulrich-Lai YM, Herman JP. Neural regulation of endocrine and autonomic stress responses. Nat Rev Neurosci 2009; 10: 397-409.

van den Heuvel OA, Veltman DJ, Groenewegen HJ, Dolan RJ, Cath DC, Boellaard B, Mesina CT, van Balkom AJ, van Oppen P, Witter MP, Lammertsma AA, van Dyck R. Amygdala activity in obsessive-compulsive disorder with contamination fear: a study with oxygen-15 water positron emission tomography. Psychiatry Res 2004; 132: $225-237$.

van den Heuvel OA, Veltman DJ, Groenewegen HJ, Witter MP, Merkelbach J, van Balkom AJ, Cath DC, van Oppen P, van Dyck R. Disorder-specific neuroanatomical differentiation of emotional Stroop interference effects in obsessive-compulsive disorder, panic disorder and hypochondriasis. Arch Gen Psychiatry 2005; 62: $922-$ 933.

van den Heuvel OA, van der Werf YD, Verhoef KM, de Wit S, Berendse HW, Wolters EC, Veltman DJ, Groenewegen HJ. Frontal-striatal abnormalities underlying behaviours in the compulsive-impulsive spectrum. J Neurol Sci 2010; 289: 55-59.

van den Heuvel OA, Mataix-Cols D, Zwitser G, Cath DC, van der Werf YD, Groenewegen HJ, van Balkom AJ, Veltman DJ. Common limbic and frontal-striatal disturbances in patients with obsessive compulsive disorder, panic disorder and hypochondriasis. Psychol Med 2011; 41: 2399-410.

van den Heuvel OA. Toward brain-based guidance of clinical practice. JAMA Psychiatry 2015; 72: 108-9.

van der Wee NJ, Ramsey NF, van Megen HJ, Denys D, Westenberg HG, Kahn RS. Spatial working memory in obsessive-compulsive disorder improves with clinical response: A functional MRI study. Eur Neuropsychopharmacol 2007; 17: 16-23.

van Holst RJ, Clark L, Veltman DJ, van den Brink W, Goudriaan AE. Enhanced striatal responses during expectancy coding in alcohol dependence. Drug Alcohol Depend 2014; 142: 204-208. 
van Marle HJ, Tendolkar I, Urner M, Verkes RJ, Fernandez G, van Wingen G. Subchronic duloxetine administrator alters the extended amygdala circuitry in healthy individuals. NeuroImage 201; 55: 825-831.

van Velzen LS, Vriend C, de Wit SJ, van den Heuvel OA. Response inhibition and interference control in obsessive-compulsive spectrum disorders. Frontiers Hum Neurosci 2014; 8: 419, doi: 10.3389/fnhum.2014.00419.

van Velzen LS, de Wit SJ, Curcic-Blake B, Cath DC, de Vries FE, Veltman DJ, van der Werf YD, van den Heuvel OA. Altered inhibition-related fronto-limbic connectivity in obsessive-compulsive disorder. Hum Brain Mapp 2015; in press (doi: 10.1002/hbm.22898)

van Wingen GA, Tendolkar I, Urner M, van Marle HJ, Denys D, Verkes RJ, Fernandez G. Short-term antidepressant administration reduces default mode and task-positive network connectivity in healthy individuals during rest. NeuroImage 2013; 88c: 47053.

Vendetti MS, Bunge SA. Evolutionary and developmental changes in the lateral frontoparietal network: a little goes a long way for higher-level cognition. Neuron 2014; 84: 906-917.

Verdejo-García A, Lawrence AJ, Clark L. Impulsivity as a vulnerability marker for substance-use disorders: review of findings from high-risk research, problem gamblers and genetic association studies. Neurosci Biobehav Rev 2008; 32: 777-810.

Via E, Cardoner N, Pujol J, Soriano-Mas C, Hernandez-Ribas R, Lopez-Sola M, Contreras-Rodriquez O, Deus J, Segalas C, Menchon JM, Soriano-Mas C, Harrison BJ. Amygdala activation and symptom dimensions in obsessive-compulsive disorder. Br J Psychiatry 2014; 204: 61-68. 
Vollstadt-Klein S, Wichert S, Rabinstein J, Buhler M, Klein O, Ende G, Hermann D, Mann K. Initial, habitual and compulsive alcohol use is characterized by a shift of cue processing from ventral to dorsal striatum. Addiction 2010; 105: 1741-1749.

Vriend C, Pattij T, van der Werf YD, Voorn P, Booij J, Rutten S, Berendse HW, van den Heuvel OA. Depression and impulse control disorders in Parkinson's disease: two sides of the same coin. Neurosci Biobehav Rev 2014; 38C: 60-71

Wendelken C, Ferrer E, Whitaker KJ, Bunge SA. Fronto-parietal network reconfiguration supports the development of reasoning ability. Cerebral Cortex 2015; in press (pii: bhv050)

White MP, Shirer WR, Molfino MJ, Tenison C, Damoisseaux JS, Greicius MD. Disordered reward processing and functional connectivity in trichotillomania: a pilot study. J Psychiatr Res 2013; 47: 1264-1272.

Whiteside SP, Port JD, Abramowitz JS. A meta-analysis of functional neuroimaging in obsessive-compulsive disorder. Psychiatry Res 2004; 132: 69-79.

Yamanishi T, Kakaaki S, Omori IM, Hashimoto N, Shinagawa Y, Hongo J, et al. Changes after behavior therapy among responsive and nonresponsive patients with obsessive-compulsive disorder. Psychiatry Research: Neuroimaging 2009; 172: 242250.

Yoo SY, Jang JH, Shin YW, Kim DJ, Park HJ, Moon WJ, Chung EC, Lee JM, Kim IY, Kim SI, Kwon JS. White matter abnormalities in drug-naïve patients with obsessivecompulsive disorder: a diffusion tensor study before and after citalopram treatment. Acta Psychiatr Scand 2007; 116: 211-9.

Zurowski B, Kordon A, Weber-Fahr W, Voderholzer U, Kuelz AK, Freyer T, et al. Relevance of orbitofrontal neurochemistry for the outcome of cognitive-behavioural therapy in patients with obsessive-compulsive disorder. Eur Arch Psychiatry Clin Neurosci 2012; 262: 617-624. 


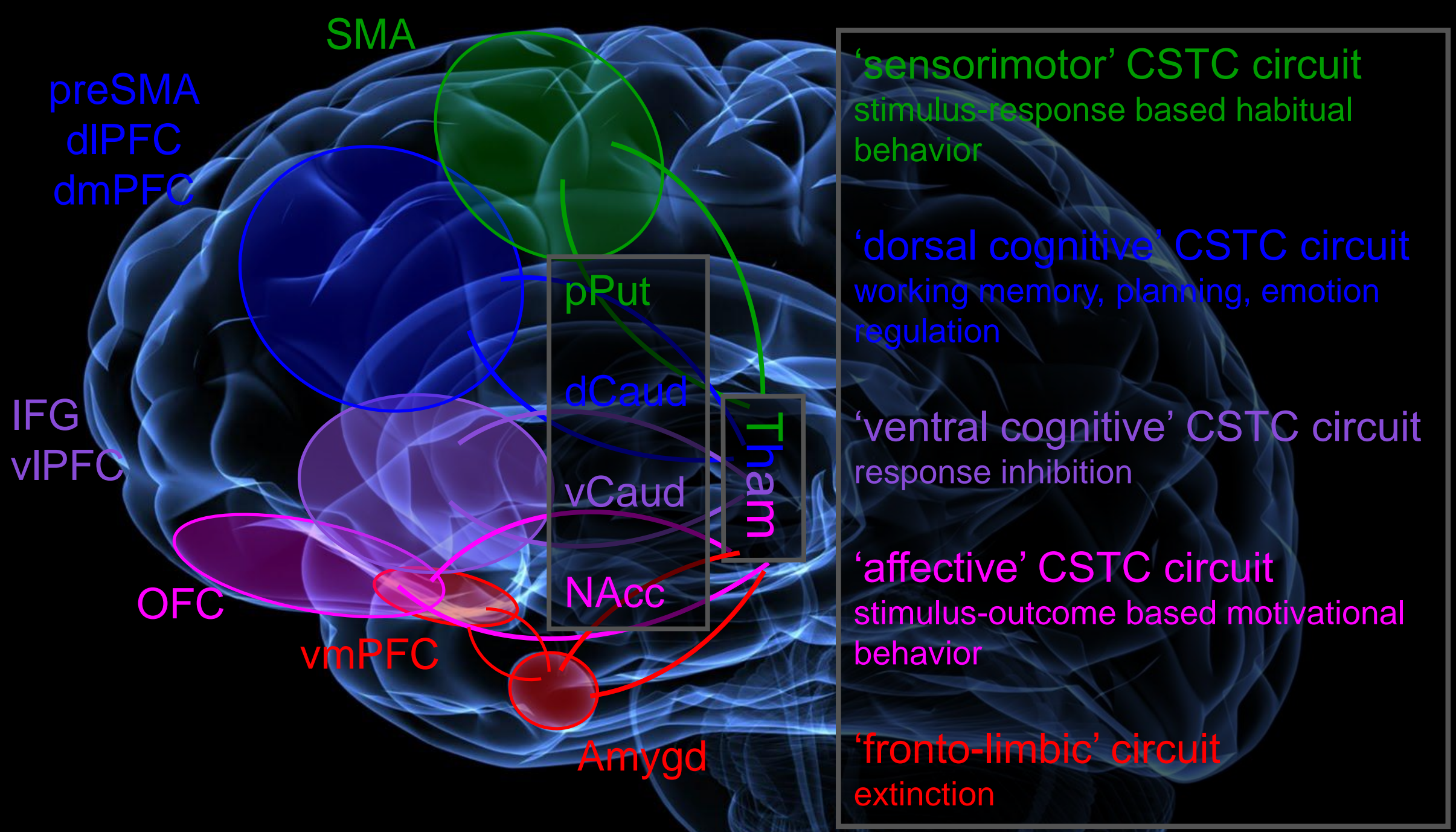

Direct pathways in CSTC circuits: disinhibition of thalamus and increased excitation of the cortex $>$ initiation / continuation of behavior

Indirect pathways in CSTC circuits: inhibition of thalamus and decreased excitation of the cortex $>$ inhibition / switching of behavior 
Title: Brain Circuitry of Compulsivity

Role of the punding source:

There was no specific funding for this review paper, other than the research funcing of the individual contributors (see acknowledgements) 


\section{Title: Brain Circuitry of Compulsivity}

Authors: Odile A. van den Heuvel ${ }^{1,2,3}$, Guido van Wingen ${ }^{4}$, Carles Soriano-Mas ${ }^{5,6}$, Pino Alonso ${ }^{5,7}$, Samuel R. Chamberlain ${ }^{8,9}$, Takashi Nakamae ${ }^{10}$, Damiaan Denys ${ }^{4}$, Anna E. Goudriaan ${ }^{11,12}$, Dick J. Veltman ${ }^{1}$

Affiliations:

${ }^{1}$ Department of Psychiatry, VU University medical center (VUmc), Amsterdam, The Netherlands

${ }^{2}$ Department of Anatomy \& Neurosciences, VUmc, Amsterdam, The Netherlands

${ }^{3}$ Department of Psychology, The Obsessive-Compulsive Disorder Team, Haukeland University Hospital, Bergen, Norway.

${ }^{4}$ Department of Psychiatry, Academic Medical Center, University of Amsterdam, Amsterdam, The Netherlands

${ }^{5}$ OCD Clinical and Research Unit, Department of Psychiatry, Bellvitge University Hospital; Bellvitge Biomedical Research Institute (IDIBELL), and CIBERSAM (Centro de Investigación en Red de Salud Mental), Carlos III Health Institute, Barcelona, Spain

${ }^{6}$ Department of Psychobiology and Methodology in Health Sciences, Universitat Autònoma de Barcelona, Spain

${ }^{7}$ Department of Clinical Sciences, Bellvitge Campus, University of Barcelona, Spain ${ }^{8}$ Department of Psychiatry, University of Cambridge, Cambridge, United Kingdom

${ }^{9}$ Cambridge and Peterborough NHS Foundation Trust (CPFT), Cambridge, United Kingdom

${ }^{10}$ Department of Psychiatry, Graduate School of Medical Science, Kyoto Prefectural University of Medicine, Kyoto, Japan

${ }^{11}$ Academic Medical Center, Department of Psychiatry, Amsterdam Institute for Addiction Research, University of Amsterdam, Amsterdam, The Netherlands

${ }^{12}$ Arkin Mental Health and Jellinek Addiction Treatment, Amsterdam, The Netherlands 
Title: Brain Circuitry of Compulsivity

Disclosures:

Dr. Chamberlain consults for Cambridge Cognition. Dr. van den Heuvel received grant support from PhotoPharmics and speaker's honorarium from Lundbeck. 
Title: Brain Circuitry of Compulsivity

Acknowledgements:

Dr. Soriano-Mas is funded by a 'Miguel Servet' contract from the Carlos III Health Institute (CP10/00604). Dr. Goudriaan is supported by a VIDI innovative research grant (grant no. 91713354) funded by the Dutch Scientific Research Association (NWO-ZonMW). Dr. Alonso was founded by the Instituto de Salut Carlos III-FIS PI14/00413. Dr. Nakamae received grant support from MEXT KAKENHI (No. 24791223 and No. 26461753. 